\title{
11 How to Design and Build the Company-Relevant Stakeholders-Based Management System
}

\section{Milestones of Designing and Building the Company- Relevant Stakeholders-Based Management System}

Without any doubt, the design and construction of a new company management system based on relevant stakeholders is a very complex undertaking, involving profound changes in the organization and management vision and approaches. It could be considered as a "breakthrough innovation", according to the recent approach of Hill and Davis (2017), rethinking traditional methods of governing and management relationships and processes. A relevant stakeholders-based management system needs to design an organization that synergistically combines humans with machines (Lesser, Reeves, Whitaker, \& Hutchinson, 2018). In Figure 11.1, we indicate the essential milestones that should be taken into consideration by the company management and the relevant stakeholders in this undertaking, in order to develop a company-relevant stakeholders' management system.

In the following sections, we will briefly present the main new elements to be reshaped within each of these milestones.

\section{Premises of the Company-Relevant Stakeholders-Based Management System Construction and Development}

Our new approach to company management focused on the relevant stakeholder is based on a set of premises. We have formulated these premises bearing in mind the company as an ecosystem, the specificity and complexity of the relevant stakeholders-based management system, and the predominant managerial approaches in the companies.

In the premises, we have introduced certain elements from analysis by other specialists, who have asked (demanded) for the promotion of management centred on the stakeholders. In Table 11.1, we present these premises. 


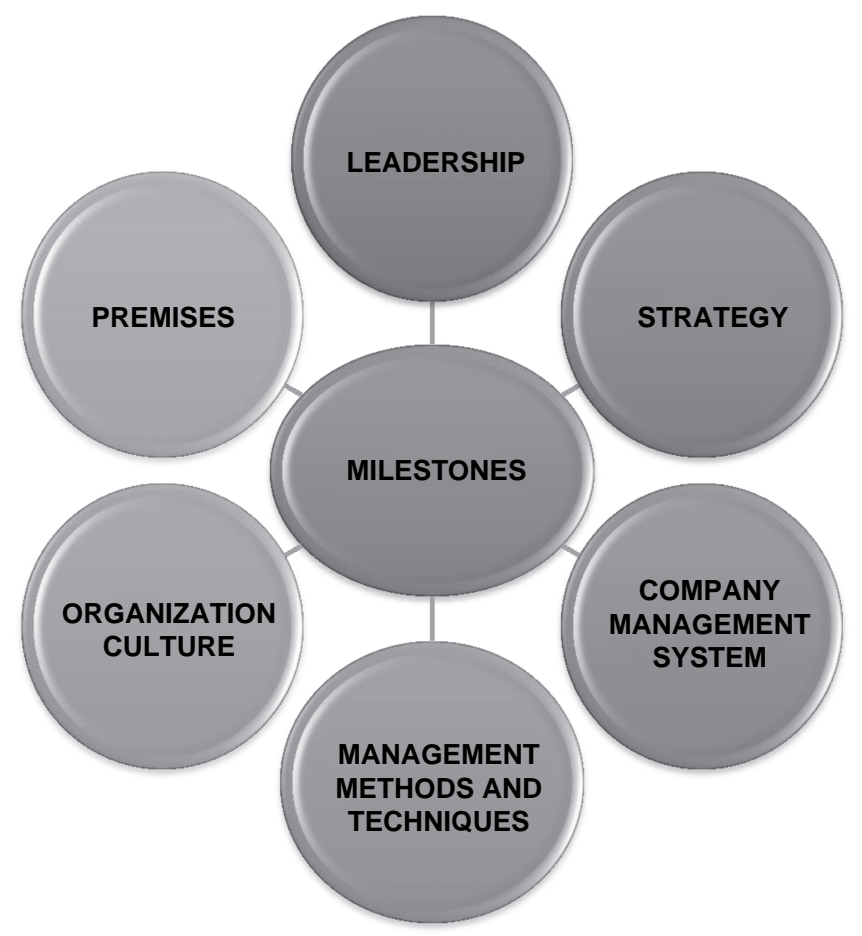

Figure 11.1 Milestones for the new company management system based on relevant stakeholders.

\section{Company Managers' Vision and Leadership Focused on the Relevant Stakeholders}

In any company, the starting point in constructing a company-relevant stakeholders-based management system is represented by the new vision and leadership of the company managers and owners. Without the vision and leadership focused on the relevant stakeholders, the new management system cannot be constructed. Recently, certain specialists demonstrated that real transformation in companies only occurs when managers' leadership achieves the combination and correlation of three models mental, business, and measurement (Bonchek \& Libert, 2017). The first to be changed is the mental model.

The new leaders, according to Ready, Cohen, Kiron, and Pring (2020), understand that people do not want to be just employees, they want to be active citizens in amazing workplace communities that are doing their best to change the world for the better.

In our opinion, the following elements represent the main steps that need to be taken in the company in order to develop a performant vision 
Table 11.1 Premises of the company-relevant stakeholders-based management design and construction

No. Premises

1. Stakeholders are essential for every company foundation, development, and competitivity, and for this reason, organization management should be focused on them.

2. The organization itself, according to Friedman and Miles (as cited in Fontaine, Haarman, \& Schmid, 2006), should be thought of as a grouping of stakeholders and the purpose of the organization should be to manage their interests, needs, and viewpoints, generating high performance for all.

3. The organization's success or failure depends on the views (perceptions) of stakeholders and also on the passing of time (Bourne, 2009).

4. Stakeholders' interests, resources and influences on the company are very unequal, varying to a great extent.

5. Identification of and taking into consideration the company-relevant stakeholders represent the starting point and the background of the stakeholders-based management.

6. Relevant stakeholder identification and management should be based on the long-term priorities of the company and the stakeholders, combined with their medium- and short-term objectives, which reflect specific needs and requirements for the next and present periods.

7. Relevant stakeholders' interests, objectives, aspirations, and expectations are multidimensional and dynamic and they should be evaluated and taken into consideration permanently, using a professional approach.

8. A stakeholders-based management system and managerial synapse represent essential approaches for performant management of the relevant company stakeholders.

9. New vision and leadership of the company managers, starting with the CEO, represent the crucial elements in the designing of the new managerial system focused on the relevant stakeholders.

10. A stakeholders-based management system, because of its specificity and complexity, needs professional processes for its design and implementation.

11. A managerial synapse represents the essential element in the stakeholdersbased management design, implementation and development.

12. Informing and training of internal relevant stakeholders and - as much as is possible - of external relevant stakeholders should precede and accompany the construction of the company stakeholders-based management system.

13. The construction and development of the stakeholders-based management system should be based on the company-relevant stakeholders' permanent consultation, collaboration, participation, and motivation.

14. For each relevant stakeholder a specific managerial synapse should be constructed and developed, based on the win-win principle, approached from the sustainable perspective.

15. The development of an organization culture focused on the relevant stakeholders during the elaboration and implementation of the company strategy focused on the relevant stakeholders is mandatory in order to achieve competitive and sustainable performance. 


\section{How to Design and Build}

Table 11.1 (Continued)

\section{No. Premises}

16. The functionality and performance of the company-relevant stakeholders' management system depend heavily on the use of specific models, methods, and techniques, focused on the relevant stakeholders, and of certain classical managerial methods and techniques, reshaped according to the new managerial approach.

17. The company-relevant stakeholders-based management system should be associated with permanent training, consultation, counselling, mentoring, tutoring, and coaching in every key field of the organization.

18. Relevant internal and external stakeholders should fulfilled periodically, evaluation and self-evaluation of the results generated from their common objectives and win-win relationships perspectives.

19. Periodically, based on the company-relevant stakeholders' evaluation and self-evaluation, the relevant stakeholders-based management system should be reviewed and developed, eliminating deficiencies and valorizing the new opportunities.

20. Obtaining information on the multidimensional performances - economic, social, ecologic, and educational - of the company and the relevant stakeholders represents the major criterion used in their evaluation and development.

and leadership capable of determining the building and implementation of a company-relevant stakeholders-based management system:

a CEO and top managers' awareness - supported by the company owners - of the decisive contribution and impact of the relevant stakeholders on the organization's existence, development, performance, and sustainability;

b Employment of consultants and trainers, in order to inform the company managers regarding the relevant stakeholders' role and impact in the company and the main approaches, methods, and techniques to be used for communication and cooperation (co-work) with them;

c Company managers, in order to be able to practise a performant leadership focused on relevant stakeholders, need to develop the following "fundamental" skills:

- share a vision that is exciting and challenging for their team/ unit/division/organization;

- translate that vision into a clear strategy about what actions to take and what not to do;

- recruit, develop and reward a team of great people to carry out the strategy;

- focus on measurable results; 
- faster innovation and learning to sustain your team for the organization to grow new leaders;

- lead yourself, know yourself, improve yourself, and manage the appropriate balance in your own life (Ashkenas \& Manville, 2018).

d Development by company managers of a new approach centred on the relevant stakeholders, capable of seizing the opportunities provided by them, and reducing their challenges and potential negative impact;

e Foundation of a special team in order to elaborate a programme for the remodelling of the organization management focused on the relevant stakeholders, in which it is recommended to include external consultants too;

$\mathrm{f}$ In this programme there should be a special module centred on the learning by company managers of the leadership skills necessary for the valorization of the relevant stakeholders' potential and for the development of effective long-term relationships with them;

g Leadership focused on company-relevant stakeholders is recommended to have the features (characteristics) presented in Table 11.2.

$\mathrm{h}$ Leadership centred on the relevant stakeholders needs to be a permanent feature of the company management and not a temporary campaign performed only at the beginning of the implementation of the relevant stakeholders-based management system.

i Periodically it is recommended to evaluate the leadership practised by the company managers, in order to identify and eliminate the deficiencies and to make improvements. Participation of external consultants and of certain relevant stakeholders in these processes could generate more rigour, creativity, and effectiveness.

In order to be able to design and implement the new vision and leadership, company managers should have five core qualities, the so-called "ADAPT dimensions" (Korn Ferry, 2019), which encompass the ability to anticipate, drive, accelerate, develop partnerships, and confer trust. New vision and leadership centred on the company-relevant stakeholders are, concomitantly, a precondition and a permanent feature of the performant company stakeholders-based management system.

\section{Design of the New Company Strategy}

Concomitantly with the remodelling of the managers' leadership, based on the new vision regarding the organization's development involving the relevant stakeholders, a new strategy should be designed in the company. The main purpose of this strategy is to enhance the competitivity and sustainability of the multi-objective company (Mitchell, Weaver, Agle, Bailey, \& Carlson, 2016) and its relevant stakeholders. A company 
Table 11.2 Features of company leadership focused on the relevant stakeholders

\section{No. Features}

1. It should be oriented toward the development of organizational change capacity with heavy involvement of the organization's relevant stakeholders; management change needs to be a core competence of the managers' leadership.

2. It is focused on the establishment and implementation of joint objectives, determined by win-win negotiation with the company-relevant stakeholders.

3. It is an "open" leadership, which overcomes the company boundaries, involving external relevant stakeholders.

4. It is an equilibrated leadership, which emphasizes the affective dimension of human relationships and - concomitantly - the operational side, regarding the fulfilment of common objectives and of the tasks, roles, competencies and responsibilities assigned to each relevant stakeholder.

5. It is an inclusiveness leadership, characterized by accepting different views, understanding diverse views, integrating other points of view, functioning well across diverse groups, facilitating engagement between fractions, strategically increasing employees' diversity and creating an inclusive culture (Fernández-Aráoz, Roscoe, \& Aramaki, 2017).

6. It is based on intense and permanent communication with all internal and external relevant stakeholders.

7. It pays respect to the company-relevant stakeholders; respect - both owned and earned - should be one of the most important leadership behaviours (Rogers, 2018).

8. It should be a transformational leadership, which seeks and explains "why" the actions tend to work well and have a range of positive outcomes.

9. It is based on emotional intelligence and emotion regulation, which are essential for the construction of an enabling context for continued and effective co-work with company-relevant stakeholders.

10. It activates shared emotional connection - called by the specialist Hernandez (2019) a "shared passion for place" - with relevant stakeholders.

11. It fulfils intensively positive motivation of the relevant stakeholders, using a large variety of approaches and tools - bonuses, profit sharing, stock option, trophies, public appreciation of work well done, flexible work schedule, simple "thank you", vouchers, tangible goods, learning and development opportunities, etc.

12. It has a very strong participative content, both for internal and external relevant stakeholders.

13. It pays great and permanent attention to valorizing the relevant stakeholders' tacit and explicit knowledge and to their intellectual capital.

14. It permanently encourages and promotes the relevant stakeholders' creativity, directed toward the achievement of common objectives, negotiated with each of them.

15. It is a dynamic leadership, continuously modifying itself, according to the stages of the implementation of changes and to the evolution of the relevant stakeholders' "maturity", and that of the other people involved. 
Table 11.2 (Continued)

\section{No. Features}

16. It fosters empathy and solidarity among all relevant stakeholders and promotes fairness and morality.

17. It is an "empowering" leadership, which works better, motivating certain types of performance, influencing people's creativity and citizenship behaviour rather than routine task performance (Lee, Willis, \& Tian, 2018).

18. It emphasizes the development of the "feeling of belonging to the company" for all relevant stakeholders, including the external ones.

19. It takes into consideration valorizing (capitalizing) the multiple possibilities provided by digitalization and digital transformation, from the perspectives of both the company and the relevant stakeholders. ${ }^{1}$

20. It focuses on the company stakeholders' responsibilities development, which has a powerful multidimensional context (economic, social, ecologic, etc.).

21. It generates, through all the above-mentioned characteristics - and especially those effectively involved - the dedication of the relevant stakeholders to the achievement of the common objectives and to the other elements win-win negotiated.

strategy based on the relevant stakeholders, in order to generate performances, should present the characteristics enumerated in Figure 11.2, briefly described below.

- Focalization on the relevant stakeholders represents the first characteristic of the new company strategy. Selection and focalization on the relevant stakeholders should be done based on the set of parameters established in the Chapter 5, Section 5.2.

- A relevant stakeholders-based strategy should be an open strategy that addresses an organization open to innovation and internal and external stakeholders, and not a "proprietary strategy". An open strategy is characterized by two dimensions - transparency and inclusion (Hautz, Seidl, \& Whittington, 2017) - both essential for effective and efficient relationships with company-relevant internal and external stakeholders. Specialists have discovered that an open strategy fosters greater growth compared with the proprietary approach (Appleyard \& Chesbrough, 2017).

- In order to generate high business performance, a relevant stakeholders' strategy should be centred on all activities that make up the company's virtual or knowledge value chain and on the relevant stakeholders that fulfilled them. This is a premise in order to maximize the total value created, both for the company and its relevant stakeholders. 


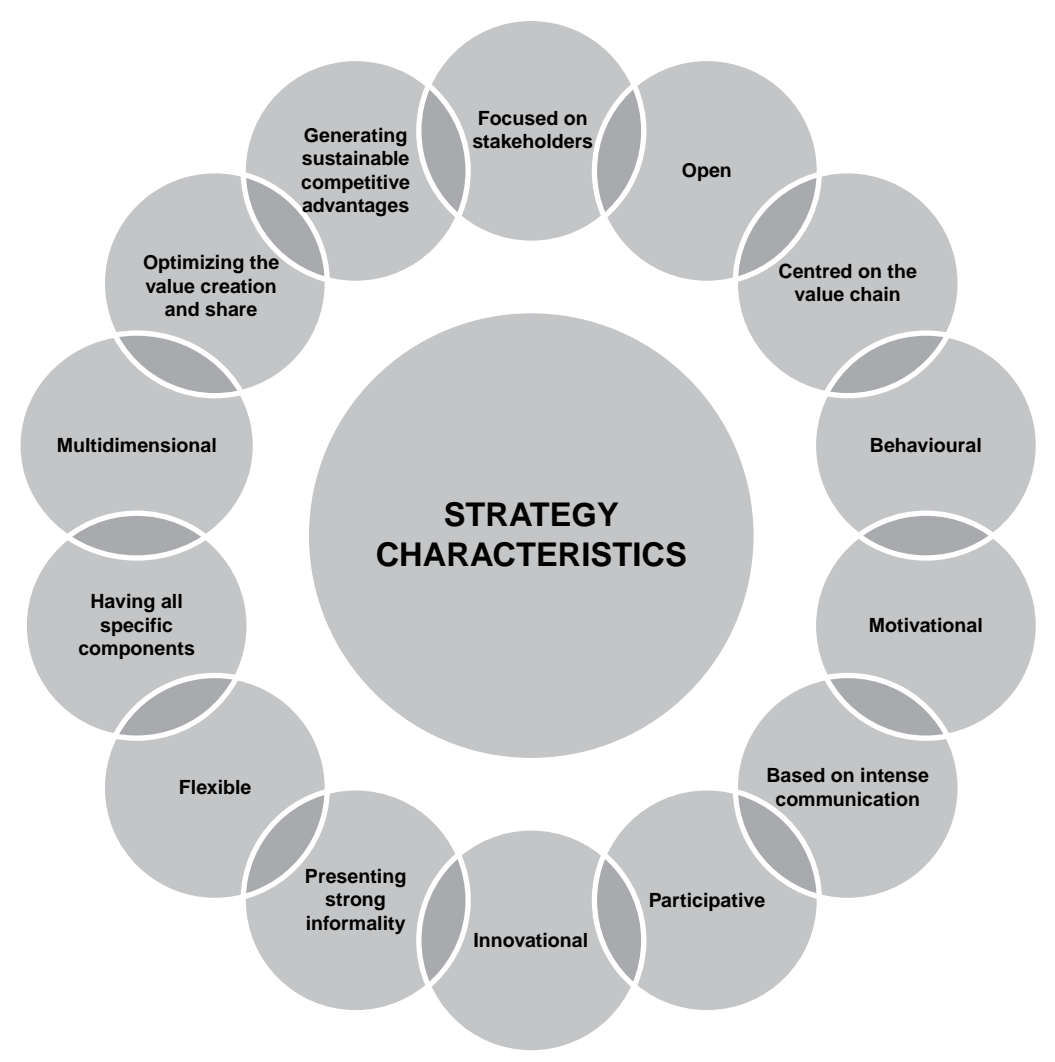

Figure 11.2 Main characteristics of the company strategy based on relevant stakeholders.

- A strategy focused on the relevant stakeholders should be a behavioural strategy that "aims" to bring realistic assumptions about human cognition, emotions, and social behaviour to the strategic management of the organization (Sibony, Lovallo, \& Powell, 2017). A behavioural strategy facilitates the "humanistic management" in the organization that is essential for the strong involvement of the internal and external stakeholders in the company's activities and development.

- A company strategy based on the relevant stakeholders should have a high motivational content. In the elaboration of the strategy, the main interests and expectations of each relevant stakeholder should be identified and taken into consideration. Common objectives of companies and relevant stakeholders represent an essential starting point in achieving this. Intrinsic and extrinsic motivations adapted to the specificity of each category of relevant stakeholders should be promoted by the company strategy. 
- The construction and implementation of a company strategy focused on the relevant stakeholders is based on intense communication. Each relevant stakeholder should be informed and asked their opinion regarding the elements of the company strategy in which he/she has a major interest and/or influence. In determining the strategy elements, where the relevant stakeholder is directly involved, it is necessary to practise win-win negotiation.

- A company strategy based on the relevant stakeholders should be participative. Each relevant stakeholder should take part in the elaboration of the strategy elements, having a direct influence on their work and performances. Participation of the relevant stakeholders in the elaboration of the company strategy not only increases its realism and potential but also contributes to faster and more effective and efficient implementation.

- The stakeholders' strategy - which itself is a business innovation should be innovational both for the company and for the relevant stakeholders. The innovation radar (Sawhney, Wolcott, \& Arroniz, 2006), which displays the 12 dimensions of business innovation involving the relevant stakeholders, can be very useful in increasing the scope and the performance of innovation.

- Compared with classical strategies, a company strategy based on relevant stakeholders is more informal due to the participation of many relevant stakeholders, especially external ones, in the elaboration of the strategy, which could not be done without using an informal approach. The elements in the strategy that refer directly to the relevant stakeholders also present a certain degree of informality. An informal approach integrated in a "humanistic management" helps to build sustainable and effective relationships with the relevant stakeholders.

- A flexible approach is a mandatory ingredient of the processes involved in the construction and implementation of a company strategy based on the relevant stakeholders. First, it is not possible to communicate and to take into consideration the main interests and expectations of many different relevant stakeholders without a flexible approach. Second, the content of the strategy should also be designed and implemented in a flexible manner, to be realistic, to be able to reflect the changing conditions in the company at the level of the relevant stakeholders and - of course - in the business environment. The VUCA environment is an increasing reality for all companies and cannot be faced without a high degree of informality and flexibility.

- A company strategy focused on the relevant stakeholders should contain all the main components - mission, fundamental objective, strategic option, resource, term, and competitive advantage rationally correlated and integrated. The absence of one or more 


\section{How to Design and Build}

components makes it impossible to operate the strategy effectively and efficiently, to generate the engagement and performance in the company and the relevant stakeholders.

- A company strategy based on the relevant stakeholders should optimize the total value in the company, taking into consideration the main interests, contributions, and expectations of all relevant stakeholders and not only the profit and/or dividend, according to business tradition, which is still predominant in the world economy. Optimization of the total value created by the company and its appropriate share with relevant stakeholders represent the realistic and mandatory business background of the new company management system.

- A strategy focused on the relevant stakeholders should be multidimensional, in terms of both content and performance. Besides the traditional business aspects, the strategy should integrate the main social, ecological, and educational aspects, which are important for the company and demanded by the relevant stakeholders.

- A company strategy based on the relevant stakeholders should be able to generate sustainable competitive advantage and not a temporary advantage (Huang, Dyerson, Wu, \& Harindranath, 2015) as has happened quite often. A company is sustainable competitive only if it takes into consideration the major interests and expectations of the relevant stakeholders. Also, the company competitive advantage, as much as is possible, should be harmonized with the competitive advantages of the external relevant stakeholders, this being a condition in order to achieve sustainable performances.

A company strategy based on the relevant stakeholders presents compared with traditional strategies - certain particularities at the level of each component (see Table 11.3).

In all processes involved in the company strategy elaboration, implementation, and operation, strategic agility is necessary, which means "the ability to remain flexible in facing new developments, to continuously adjust the company strategic direction and to develop innovative ways to create value" (Weber \& Tarba, 2014). A company strategy based on the relevant stakeholders should be coupled with organizational agility, because "only when everything is working well together can value be created and captured and durable competitive advantage realized" (Teece, Peteraf, \& Leih, 2016).

A company strategy focused on the relevant stakeholders, like any up-todate strategy, should take into consideration the use of digital technologies (AI, robots, Internet of Things [IOT], and others). In this respect, it is essential to focus the strategy not on digital but on the transformation generated by it. As recently pointed out by a specialist, "technology does not provide value to a business. It never has (except for technology in products). 
Table 11.3 Particularities of the company strategy based on the relevant stakeholders, at the level of its components

\begin{tabular}{|c|c|c|}
\hline No. & Strategy Components & Particularities \\
\hline 1. & Company mission & $\begin{array}{l}\text { - It takes into consideration, concomitantly, the } \\
\text { future of the company and of the external } \\
\text { relevant stakeholders, using an integrative } \\
\text { approach; }\end{array}$ \\
\hline 2. & $\begin{array}{c}\text { Fundamental } \\
\text { objectives }^{2}\end{array}$ & $\begin{array}{l}\text { - All objectives reflect the common essential } \\
\text { interests of the company and of the relevant } \\
\text { stakeholders; } \\
\text { - Common objectives are the result of win-win } \\
\text { negotiation between the company and the } \\
\text { relevant stakeholders; } \\
\text { - In the special circumstances, besides common } \\
\text { objectives, certain specific objectives of the } \\
\text { most important external relevant stakeholders } \\
\text { can be included in the strategy; }\end{array}$ \\
\hline 3. & Strategic options & $\begin{array}{l}\text { - In the strategy is formulated, as the first } \\
\text { company strategic option, the construction } \\
\text { and the development of sustainable relation- } \\
\text { ships with all relevant stakeholders; } \\
\text { - All other strategic options take into consid- } \\
\text { eration the direct and intense participation } \\
\text { of the relevant stakeholders in their imple- } \\
\text { mentation; } \\
\text { - In the special circumstances, a strategic option } \\
\text { can be formulated regarding only a certain } \\
\text { relevant stakeholder that has an exceptional } \\
\text { involvement in, and impact on, the company's } \\
\text { performance; }\end{array}$ \\
\hline 4. & Resources & $\begin{array}{l}\text { - Within resources allocated, besides company } \\
\text { resources, an important share is represented by } \\
\text { the relevant stakeholders' resources, specified } \\
\text { as attracted resources; } \\
\text { - When the external relevant stakeholders' } \\
\text { resources are substantial, they can be specified } \\
\text { separately; } \\
\text { - Knowledge and information about the com- } \\
\text { pany and relevant stakeholders represent a } \\
\text { high weight in the total strategy resources; }\end{array}$ \\
\hline 5. & Terms & $\begin{array}{l}\text { - In the strategy, terms can be established sepa- } \\
\text { rately for certain relevant stakeholders; } \\
\text { this usually happens when strategic options } \\
\text { are specified in the strategy for the relevant } \\
\text { stakeholders; } \\
\text { - Terms are reviewed yearly in order to take into } \\
\text { consideration the company and the relevant } \\
\text { stakeholders' unexpected evolutions and the } \\
\text { environmental challenges; }\end{array}$ \\
\hline
\end{tabular}


Table 11.3 (Continued)

\begin{tabular}{lll}
\hline No. & Strategy Components & Particularities \\
\hline $6 . \quad$ Competitive & - Company competitive advantage takes into \\
advantage & consideration, directly and, especially, indir- \\
& ectly, the specific competitive advantages of \\
& the external relevant stakeholders; in fact, \\
& competitive advantage planned by a company \\
& strategy is a "mixed competitive advantage", \\
& reflecting both the company and external \\
& relevant stakeholders' interests and potentials; \\
& The company competitive advantage is always \\
& multidimensional, reflecting the diversity of \\
& the relevant stakeholders' essential interests \\
& and contributions.
\end{tabular}

Instead, technology value comes from doing business differently because technology makes it possible" (Westerman, 2018).

Another significant remark deals with the high complexity and difficulty in elaborating and implementing a company strategy based on the relevant stakeholders. There are mainly three causes that generate them:

a The taking into consideration and the participation of many and diversified internal and external relevant stakeholders in the strategic processes;

b Some of the main interests and expectations of certain relevant stakeholders are different from the company ones, or even opposite;

c Among the company's external relevant stakeholders sometimes co-opetition occurs too, and the concurrence involved makes the harmonization of the objectives, strategic options, resources, terms, and competitive advantages within the company strategy based on the relevant stakeholders very difficult.

Finally, we can conclude that a company strategy focused on the relevant stakeholders, with its many particularities and high complexity, represents an essential element without which the design, construction and implementation of a new company management system based on relevant stakeholders is not possible.

\section{Remodelling of the Company Management System}

A new company vision, strategy, and leadership focused on the relevant stakeholders are not enough for successful use of the new management 
system. Remodelling of the company management system and its subsystems should be based on organizational agility, using a flexible approach in all processes involved (Harraf, Wanasika, Tate, \& Talbott, 2015; Weber \& Tarba, 2014). Concomitantly, it is necessary to employ dynamic responsibilities, "fulfilling the framework that guides managers with respect to when and how to manage" (Teece et al., 2016). Dynamic capabilities are essential for ensuring the enterprise's long-term viability, namely sensing, seizing and transforming (Healey \& Hodgkinson, 2017). Remodelling of the organization's management system should be centred on the company value chain activities, in order to maximize the contribution to the increase of the company's performance and competitivity. Because the stakeholders-based management system is radically different from "classical" management systems - as we have already argued - it is necessary to redesign all its main components. This means that its five subsystems should be remodelled (see Figure 11.3).

For each of these subsystems, we will indicate some of the major changes that must be implemented.

a In the methodological managerial subsystem, four categories of changes should be operated:

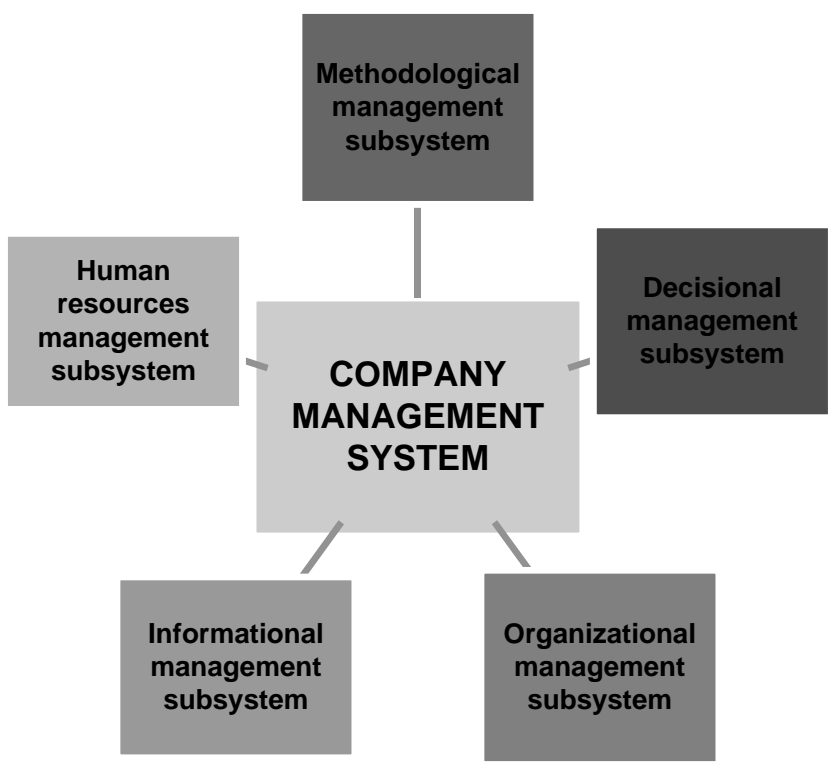

Figure 11.3 Subsystems of the company management system. 
- integration in this managerial subsystem of the approaches, methods, and techniques used in recent decades in companies to deal with stakeholders. Of course, these management tools should be adapted to the specificity of the managerial synapse and of the stakeholders-based management system. We want to point out that there are many such methods and techniques, like stakeholder analysis, stakeholder circle, intra-stakeholder alliance, stakeholder co-creative network, stakeholder analysis matrix, four-factor stakeholder model, stakeholder communication template, stakeholder management plan smartsheet, stakeholder strategy matrix, stakeholder focus group, advisory stakeholder panel, stakeholder matrix guide, stakeholder management web, stakeholder performance scorecard, etc. A list of more than 50 such stakeholder management tools is presented in Section 11.6.

- Design of new management tools focused on the relevant internal and external stakeholders. They are essential both for the managerial synapse and relevant stakeholders-based management system in order to fully take advantage of their high specificity and potential to enhance performances.

- Remodelling of some "classical" managerial methods and techniques taking into consideration the specificity of the stakeholders-based management system and of the last development in the company environment. Among these managerial tools we mention: SWOT analysis, business plan, benchmarking, brainstorming, career plan, decisional simulation, delegation, SMART model, root cause analysis, requirement workshop, checklist, job enrichment, organizational chart, scenario method, etc. Of course, not all "classical" management tools can be remodelled in order to be successfully used in the stakeholders-based management system, but for many of these it is possible. In Section 11.5, we make a selection of more than 60 managerial "classical" tools that might be remodelled according to the specificity of the managerial synapse and/or stakeholdersbased management system.

- Elimination from the managerial tools integrated in the methodological management subsystem of those methods and techniques, which by their nature are not compatible with the new managerial approach focused on the relevant stakeholders and cannot be successfully used. We mention from this category MTM, work factory, timing technique, instant observations, etc. These managerial tools are based on excessive hierarchy, on constraints, or on the threat to people.

b In the decisional managerial subsystem, there are many significant changes, like the following: 
- Development of new categories of decisions and decisional flows associated with the relevant stakeholders, most of them with external relevant stakeholders, which could not be found usually in the company management system;

- Major decisions involving the relevant stakeholders are based on win-win negotiation and are focused on the common objectives planned, normally at the beginning of the year. The content and the itinerary of the decisional processes involved are changed to a large extent, compared with the previous period;

- Decisional processes have a highly participative dimension, relevant stakeholders taking part actively in their progress, and communicating intensively in order to harmonize the objectives to be fulfilled and to establish ways to cooperate and to implement them;

- Many decisions involve, relatively frequently, not only company managers and their subordinates but also clients, customers, investors, designers, consultants, trainers, and other relevant stakeholders from outside the company;

- All changes mentioned are necessary for the elaboration of a decisional sheet for every managerial synapse and each company manager. On the decisional sheet (see Table 11.4), it is essential to indicate the methods and techniques to be used in order to make effective and efficient decisions for the company and for the relevant stakeholders.

The changes enumerated determine significant modifications in the decisional subsystem work and performances, making it more complex and performant for the company and its relevant stakeholders.

c The company organizational management subsystem should be significantly modified, using an agility approach to dynamic work design (Repenning, Kieffer, \& Repenning, 2018). It is recommended to design a "participative centralization" subsystem type (Adler, Heckscher, \& Prusak, 2011), which means being based on a new type of authority structure, which involves overlapping spheres of influence between managerial synapses, and between these and other organizational components of the company and of the external relevant stakeholders. We indicate some of the major changes to be made:

Table 11.4 Decisional sheet

\begin{tabular}{ccl}
\hline No. Decisions & Periodicity & $\begin{array}{l}\text { Recommended Observations } \\
\text { Decisional }\end{array}$ \\
\cline { 2 - 3 } & Yearly Monthly Weekly Daily & Tools \\
\hline
\end{tabular}

1.

2.

3. 
- Construction of the new organizational component - managerial synapse - which has an essential role and impact in the company organizational structure. A managerial synapse represents the specific organizational way to configure the work processes and relationships at the level of each relevant stakeholder, capable of generating a positive identity at work. A managerial synapse is constructed as a multidimensional context. We do not focus on its characteristics, because these have been presented in Chapter 5, Sections 5.3, 5.4, and 5.5, where we have also proposed a guide for performant managerial synapse construction, work and performance.

- Foundation, within the organization, of new managerial bodies company participative relevant stakeholders' council and departmental participative relevant stakeholders' committees - specific to the relevant stakeholders-based management system. Information regarding these bodies is presented in Chapter 9, Section 9.3.

- Development of new categories of very intense organizational relationships between the relevant stakeholders inside the managerial synapse and between this and other organizational components of the company.

- Extension of the company's organizational subsystem, beyond the organization boundaries, through the inclusion of external relevant stakeholders.

- Change in the content and functionality of all components of the organizational subsystem - job, function, span of control, department, hierarchical level, organizational relationships because of the impact of the relevant stakeholders' focalization in the company. Within each of them appear new specific common objectives, roles, tasks, competences, responsibilities, flows, etc.

- Diminution of the hierarchical intensity of the organizational management subsystem, because the establishment of the common objectives and of the set of tasks, competences and responsibilities in every managerial synapse is the result of win-win negotiation and intense consultation, and not imposed by ordering.

- Extension of the frequency of non-hierarchical organizational relationships - functional and cooperative relationships. We point out that in the stakeholders-based management system, in particular, the cooperation relationships are much more frequent and more influential than other types of company management systems. Frequently, the cooperation relationships are integrated in networks that involve relevant stakeholders.

- Increase of the role and impact of informal organizational 
elements within the organizational subsystem, which facilitates cooperation among stakeholders and between them and the other company components. Informal organizational elements contribute significantly to the needed flexibility within the stakeholders-based management system.

- All organizational documents of the company - job description, attribution diagrams, organizational handbooks, organigrams, etc. - are redesigned in order to incorporate the new organizational elements of the stakeholders-based management system.

The organizational management subsystem in a company that implements the stakeholders-based management system is radically different from organizational management subsystems in "classical" companies.

d Within the company's informational management subsystem, the following major changes should also be made:

- Extension of the informational subsystem beyond company boundaries, external relevant stakeholders becoming major information receivers and issuers for the organization.

- The company's information nature, structure and information procedures also change, due to the incorporation of many new elements generated by the establishment of common objectives, win-win negotiation, reasonable compromise fulfilment, etc.

- Appearance of new information files and databases on the information flows and circuits involved in networking with internal relevant stakeholders and - especially - with external relevant stakeholders.

- Information used in the company comprises, to a large extent, knowledge of the relevant internal and external stakeholders that intensively share it, in accordance with the new management system's specificity.

- The company's information subsystem is characterized by frequent use of the new informational elements generated by digitalization and digital transformation, without which it is not possible to develop intensive and effective relationships with all internal and external company-relevant stakeholders.

- Increase the informational management subsystem informal dimension because of the specificity of human relationships within managerial synapses, and between them and the other company components.

The new company information management subsystem is more complex, flexible, and effective due to the features of the stakeholdersbased management system. 


\section{How to Design and Build}

e In the human resources management subsystem, multiple changes are necessary, including the following:

- Focalization of the human resources management on the companyrelevant stakeholders, both internal and external, increasing their scope and changing partially the content and how it operates. It is recommended to use the agile approach, which, according to some specialists (Cappelli \& Tavis, 2018), "is now transforming how organizations hire, develop and manage their people".

- Modification to a certain extent of the criteria for internal stakeholders' selection, integration, motivation, evaluation, training, promotion, etc., taking into consideration the specificity of human relationships within the managerial synapse, which are characterized by intense communication and consultation, win-win negotiation, reciprocity, high participation in decisional processes and actions, etc.

- Foundation in the human resources management of a new field, dealing with the external relevant stakeholders, which will integrate many elements of human resources management that are quite different from the management of company managers and subordinates. The mission of this new field should be to facilitate the creation and the development of effective and efficient sustainable relationships with internal and external relevant stakeholders, to increase the meaningfulness work for each of them (Bailey \& Madden, 2016) and to develop company-relevant stakeholders' responsibilities.

- Increase of the importance and intensity of motivation, approached as a multifaceted process and designed taking into consideration the specificity of the managerial synapses and of the stakeholders-based management system as a whole. Moral motivations tend to increase and diversify concomitantly with the increase of relevant stakeholders' participation in sharing the total value created by the company.

- Design and fulfilment of special approaches and programmes for training, mentoring, coaching, counselling, etc. the company employees and the external relevant stakeholders, with the aim of developing their qualities, skills, and knowledge with a major impact on the creation and development of managerial synapses.

The company management human resources subsystem plays a very important role in the successful implementation of the stakeholders-based management system.

Reshaping of the five main components of the company management system should be achieved using a combination of "top-down" and "bottom-up" approaches (Heyden, Fourné, Koene, Werkman, \& 
Ansari, 2017), with intense participation by all relevant stakeholders. Such participation is indispensable for the construction of the stakeholders-based management system. Without comprehensive and continued participation of each relevant stakeholder in all phases of the managerial synapse construction, in all management system components - decisional, organizational, informational, etc. - it is not possible to generate an effective and efficient company managerial mechanism. Nothing can replace the direct and intense participation of each relevant stakeholder in determining the common objectives, win-win negotiation or reciprocal compromise fulfilment. Relevant stakeholders' participation in the managerial synapse construction and in the other elements of the stakeholders-based management system has a powerful motivational content. At the same time, the participation is an irreplaceable condition so that relevant stakeholders can continue to make a great contribution with all their resources to the company work and to maximum use of their qualities, energy and competences to achieve the common objectives, generating high performance for them and the organization. Participation develops "stakeholder organization ownership" and responsibility of the new management mechanisms.

High functionality and performance of the stakeholders-based management system is conditioned by the harmonization at the level of the whole company between all its components. In order to accomplish harmonization it is essential to operate on the following two levels:

- Harmonization among the five managerial subsystems methodological-managerial, decisional, organizational, informational and human resources management. Harmonization should be done at the level of each company component, every external relevant stakeholder, and each managerial synapse. Special attention should be paid to the harmonization of those elements in every company department and at the level of the entire organization.

- Harmonization between the new management elements, specific to the stakeholders-based management system, and the other elements of the company management. At the level of every organization component, of each relevant internal and external stakeholder, the new organizational, decisional, informational, etc. elements should be strongly correlated with the other processes and relationships fulfilled in the company. This harmonization should be fully completed, in order to accomplish "de facto" integration of all work processes and relationships involved. It is absolutely essential that mismatches do not exist between the management elements specific to the stakeholders' management and the other managerial processes and relationships. 


\section{How to Design and Build}

Harmonization of all components of the company stakeholders-based management system, using an agile approach, can contribute in the development of the organization's internal innovative environment, centred on the relevant stakeholders.

The elements presented reflect the novelty and the complexity of the company-relevant stakeholders-based management achievement. Companies - especially large and medium-sized ones - in order to build a performant new management system, an agile organization, need to use a professional undertaking involving consultants specialized in the design and development of organization managerial systems who have the vision, know-how and the dynamic capabilities demanded by such a project, and are able to take into consideration the complex changes generated by the COVID-19 pandemic.

\section{Approaches, Methods, and Techniques Useful in the Construction and Operation of the Company-Relevant Stakeholders-Based Management System}

As we have argued, the company-relevant stakeholders-based management system is a new organization management system that is completely different from all previous management systems used in companies. Moreover, in the construction, use and development of this system, quite a large number of the managerial approaches, methods and techniques from the present company practice might be employed. Taking into consideration their content, they can be grouped into two categories:

- approaches, methods and techniques created in the last few decades, focused on the organization stakeholders. These take into consideration more or less stakeholders' specificity;

- methods and techniques from "classical" management, which could be used, of course, with adaptation in the stakeholders-based management system.

In the next few pages, we will selectively enumerate both categories of methodological tools, which could be very helpful in the new company management system.

I Specific stakeholder managerial approaches, models, methods, and techniques

In the international literature dedicated to stakeholders and their approaches, thousands of studies and books have been published in recent decades. The majority of them have a theoretical content and - to a less extent - they present results of empirical research. The review of a few 
hundred studies and books elaborated by well-known specialists in their field and of organization consultant sites and of other bodies that deal with company management and stakeholders allows us to identify quite a few stakeholders' approaches, models, methods, and techniques. We have made a selection of some methodological tools that might be used in the stakeholders-based management system. In Table 11.5, we list them, indicating whether they are useful for the managerial synapse and/or for the stakeholders-based management system.

We want to make it clear that we do not pretend that we have selected the most representative or the best stakeholder approaches, models, methods, and techniques to be employed in companies. Our selection like any qualitative selection - is subjective. But the tools selected are useful in the building and functioning of a stakeholders' management system. Also, they can help practitioners from the companies in stakeholder management, even if they do not utilize the new specific managerial mechanisms proposed by us - the stakeholders-based management system and managerial synapse.

In regard to the use of specific tools for the company stakeholders' approach incorporated in Table 11.5, in the company-relevant stakeholdersbased management system, we should outline two aspects:

a In every company, these tools should be used in a specific manner, taking into consideration organization and stakeholders' particularities. Each of them should be adapted to company-relevant stakeholders-based management specificity, taking into consideration at least the following elements:

- The stakeholders involved are relevant stakeholders, who need to be approached in a specific manner, different from other types of the company stakeholder (salient, primary, etc.) used by other specialists;

- The managerial synapse, the basic component of the new system used for each relevant stakeholder, is an innovational managerial mechanism with very high particularities, which determines quite often profound changes in the employment of the previous managerial stakeholder tools;

- The company-relevant stakeholders-based management system has a specific structural and functional content, and the management processes and relationships are remodelled differently compared with the management processes and relationships used so far in the previous stakeholder approaches.

For this reason, the managerial tools should be modified in order to fit and to generate performance within the company stakeholders-based 


\section{How to Design and Build}

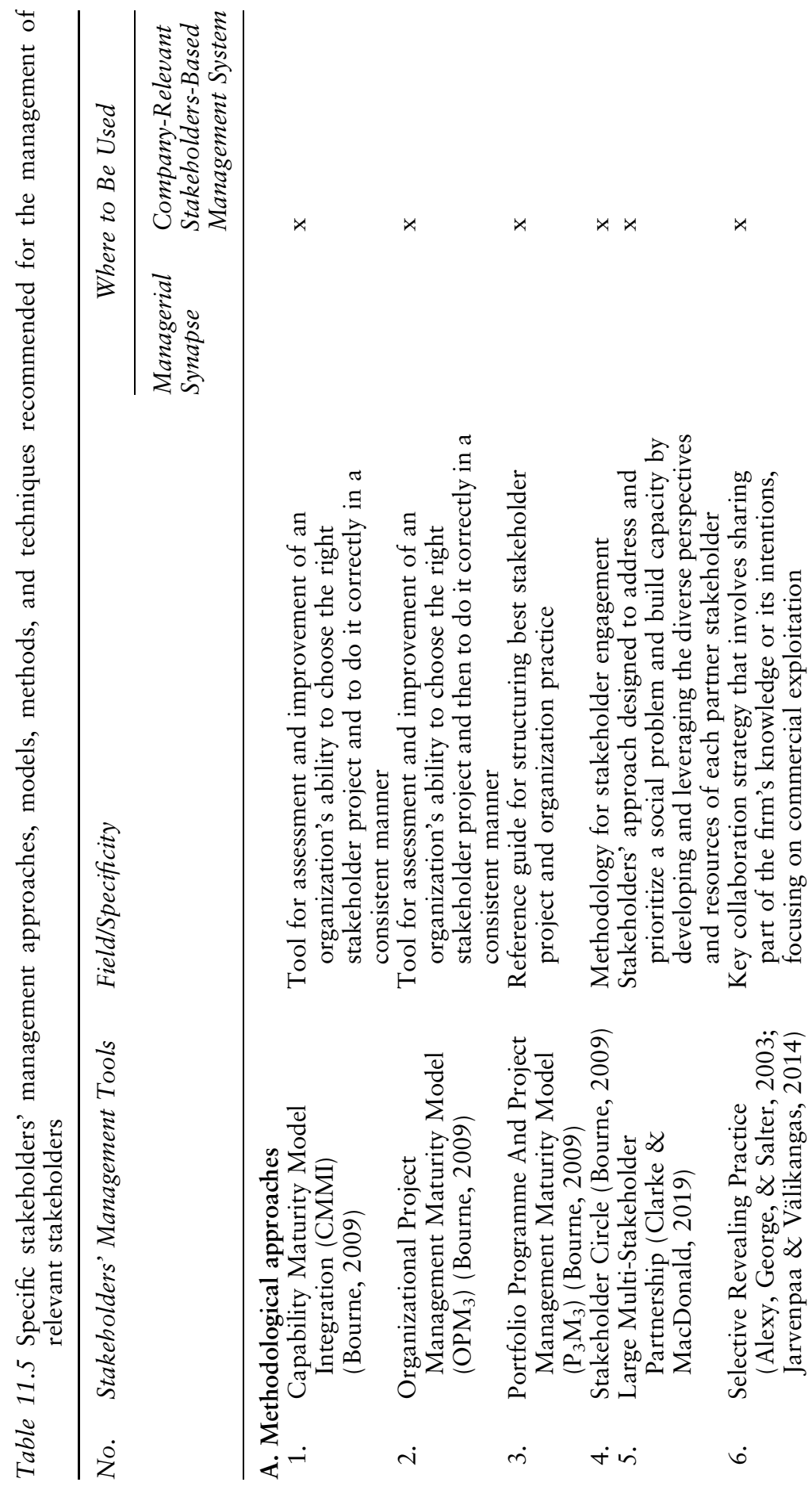




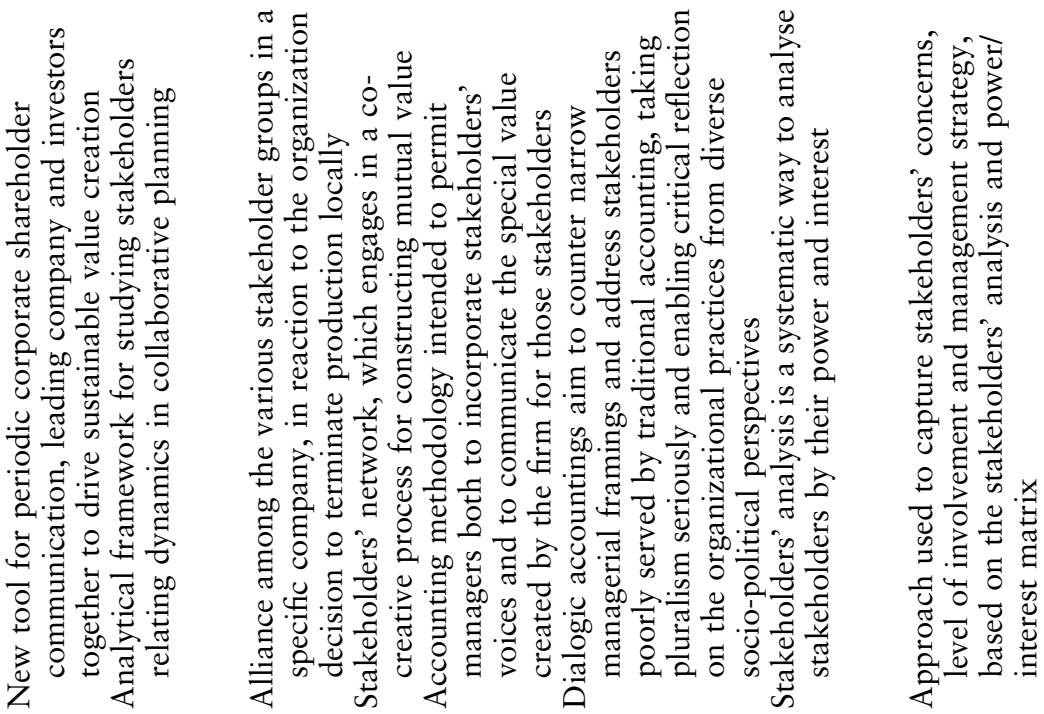

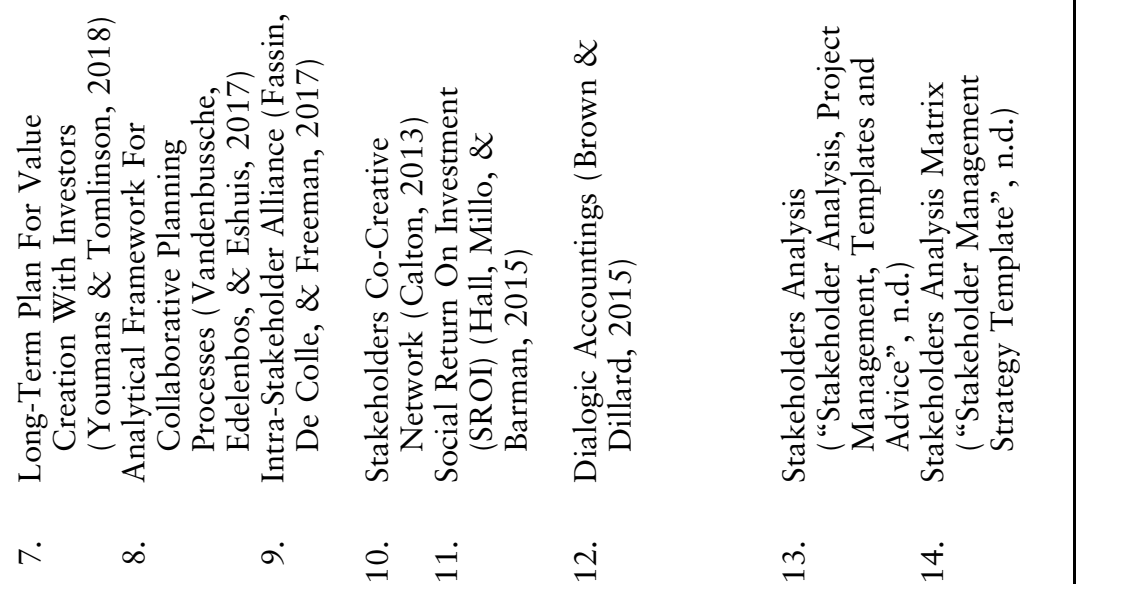




\section{How to Design and Build}

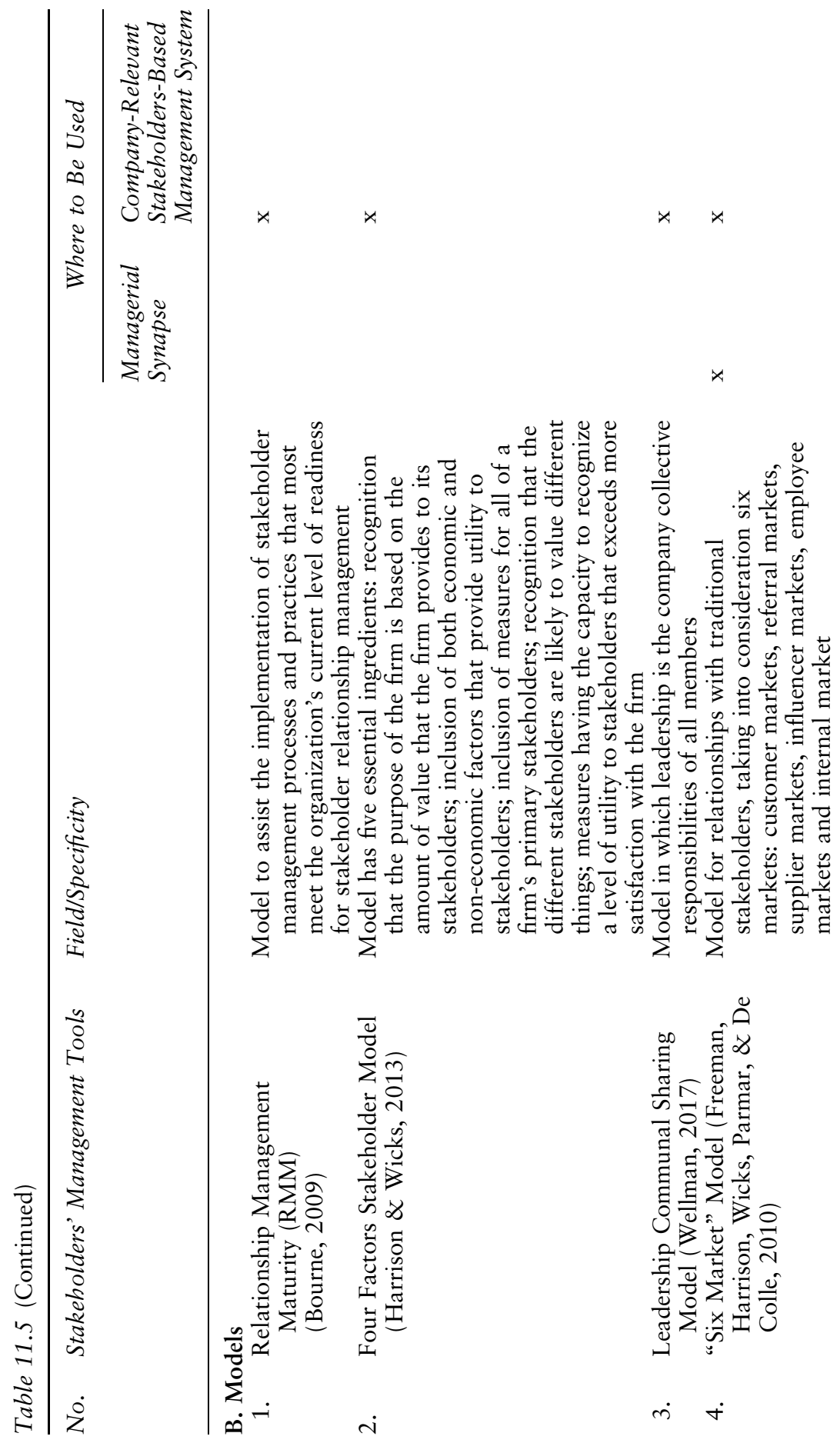




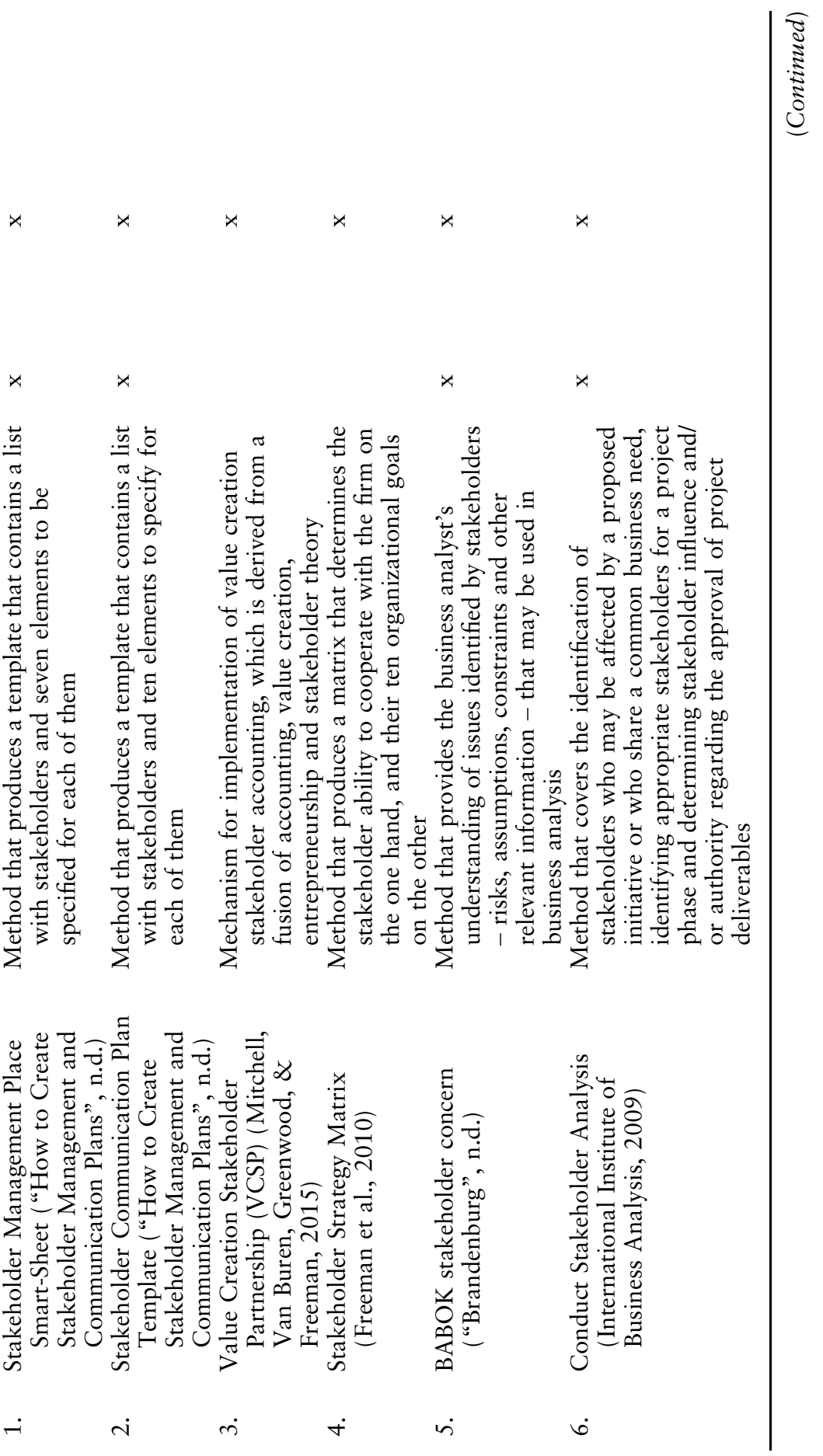




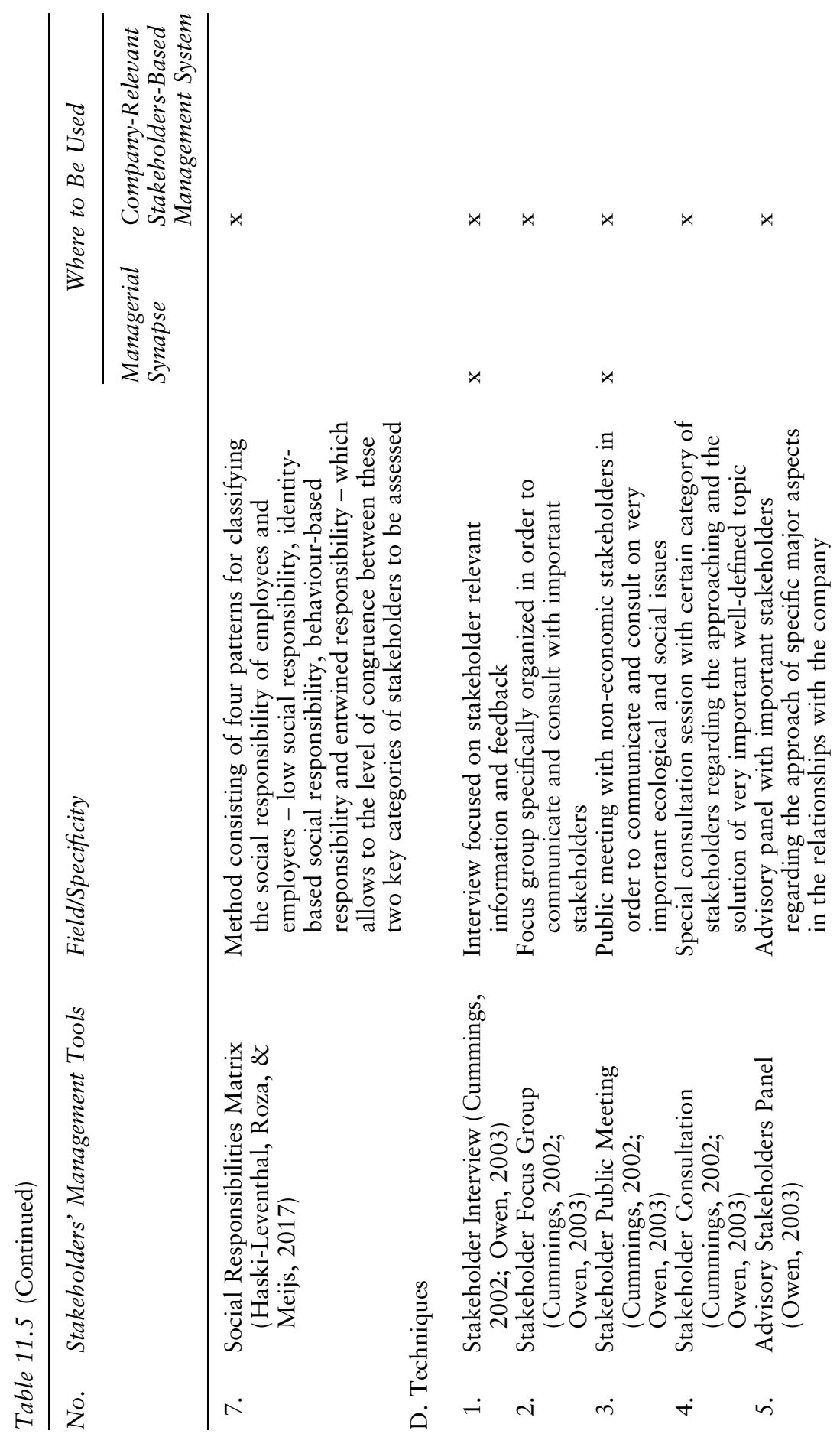




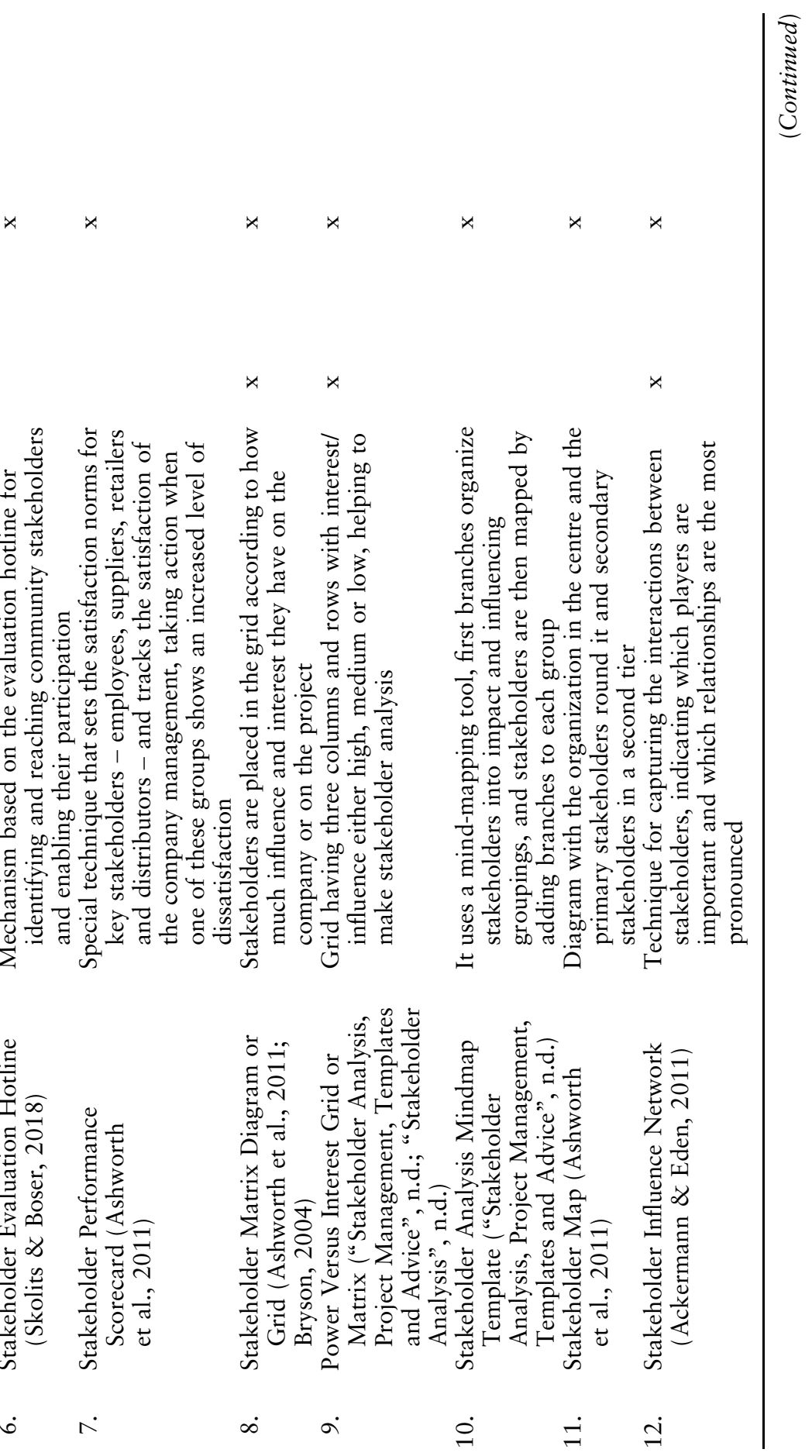




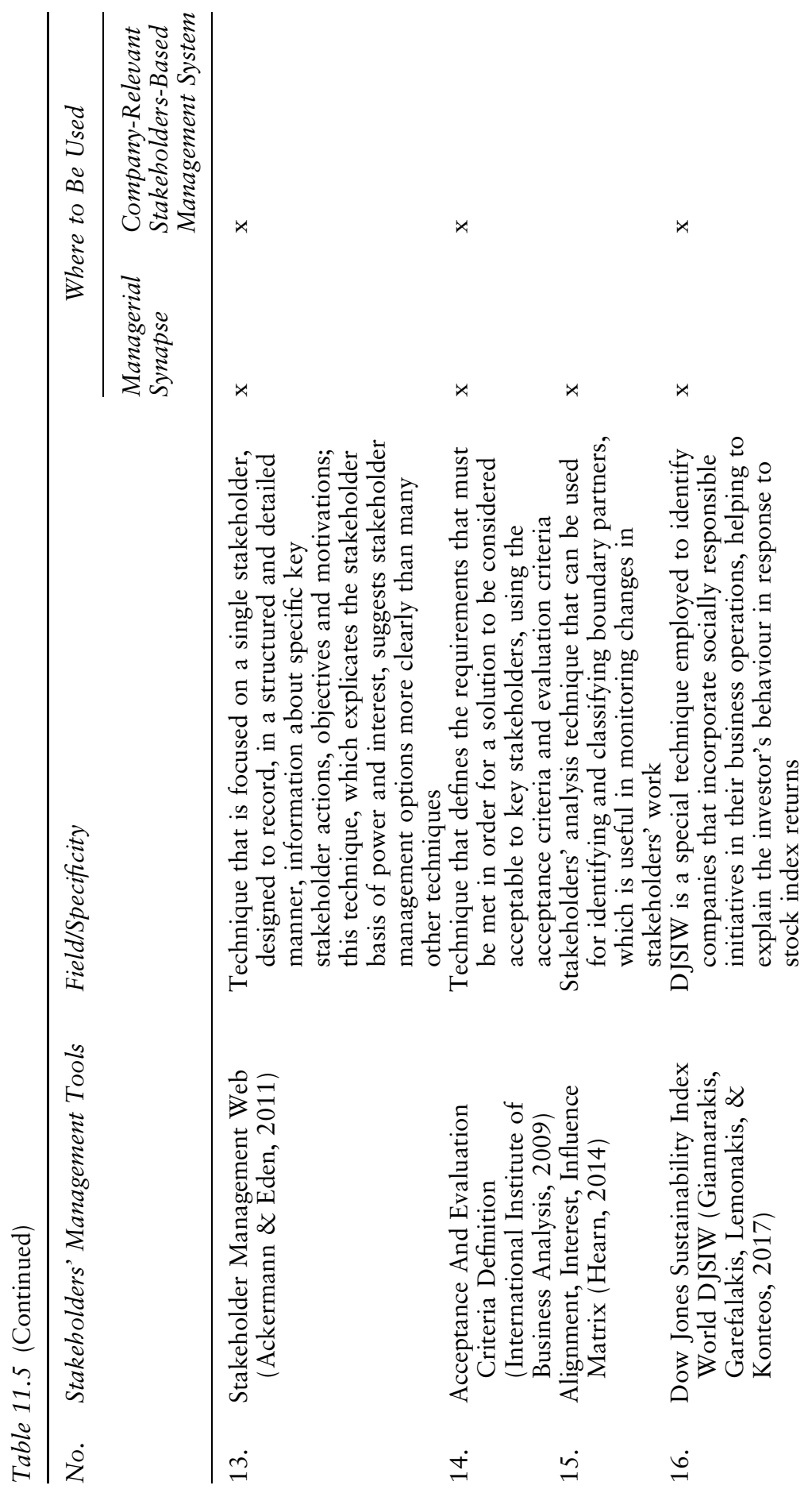




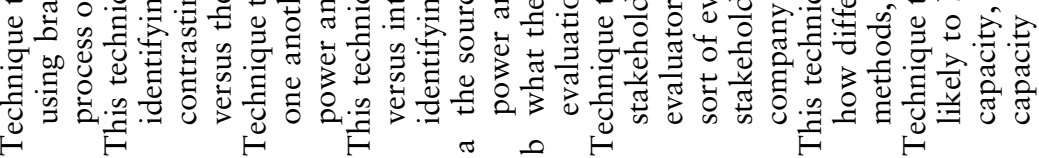

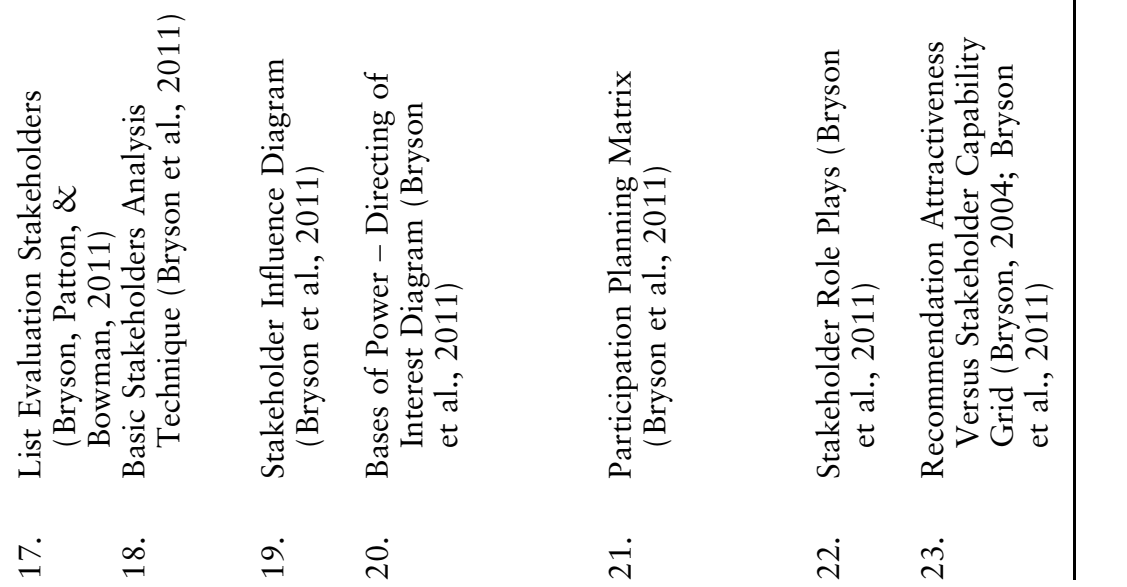


344 How to Design and Build

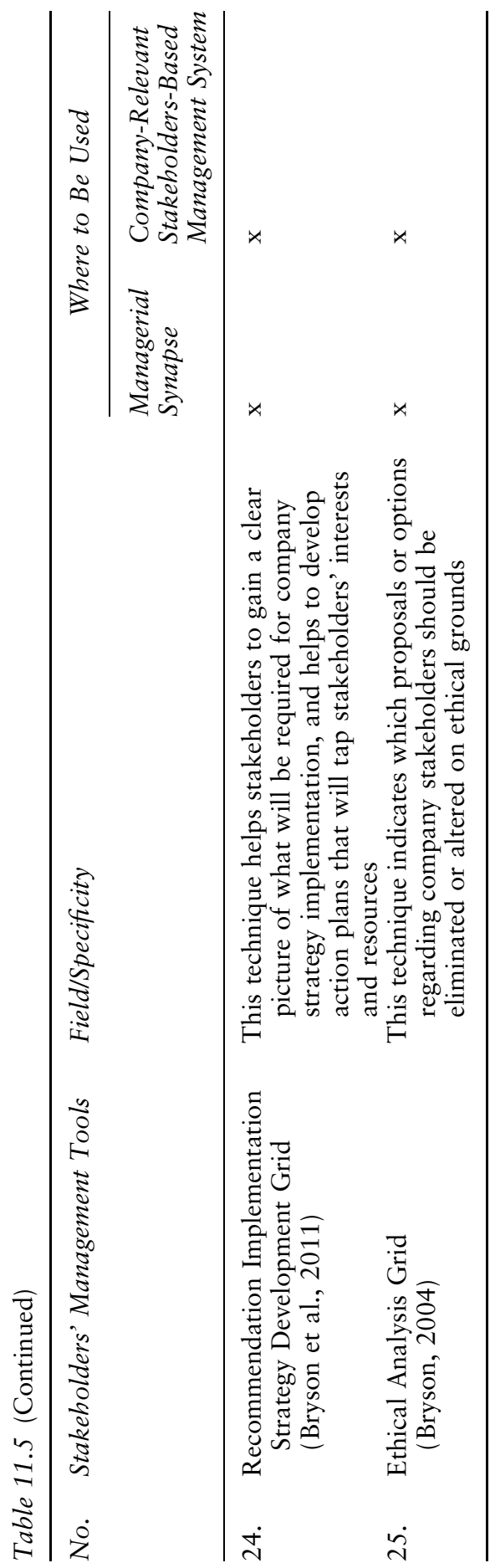


management system. In practice, it is necessary to adopt a creative approach and use each stakeholder tool in order to obtain the maximum positive effects at the level of the company and every relevant stakeholder.

b In using these tools, company managers should integrate, as much as possible, the new communication technologies - including blogging, texting, podcasting, and video posting - especially in the relationships with external stakeholders. Such an approach is very useful in order to communicate better with company stakeholders, to use the stakeholders' knowledge and information to a higher level, and to develop faster and better work relationships with them.

II Classical managerial methods and techniques recommended to be used in the company-relevant stakeholders-based management system

As a result of our management analysis of the list of 136 management classical methodological tools (International Institute of Business Analysis, 2009; Nicolescu \& Verboncu, 2008) relatively frequently used in companies, we completed a selection of 62 items incorporated in Table 11.6, indicating where we believe they should be used at the level of the stakeholders-based management system and/or the managerial synapse.

We want to specify that some of these methods and techniques have already been used by company management in the stakeholders' approach - brainstorming, benchmarking, interview, questionnaire, SWOT analysis, focus group, flow diagram, document analysis, etc. They have been employed either as such or integrated in the specific stakeholder tools. Of course, this list is just a limited selection of managerial approaches, methods, and techniques. Without any doubt, there are other managerial "classical" management tools that could be used in the stakeholders-based management system. In order to use them within this new management system and to obtain maximum positive effects, are recommended to adapt them to the specificity of the new system. Adaptation should be based on in-depth analysis of each company management and its internal and external environment, of the relevant stakeholders taken into consideration. Quite often, adaptation should have a consistent innovational content in order to generate sustainable development and performances for the company and the relevant stakeholders. 


\section{How to Design and Build}

Table 11.6 "Classical" managerial tools that could be used in the companyrelevant stakeholders-based management system

\begin{tabular}{|c|c|c|c|}
\hline & Management Tools & $\begin{array}{l}\text { Managerial } \\
\text { Synapse } \\
2\end{array}$ & $\begin{array}{l}\text { Company-Relevant } \\
\text { Stakeholders-Based } \\
\text { Management System } \\
3\end{array}$ \\
\hline 1. & $\mathrm{ABC}$ & $\mathrm{x}$ & $\mathrm{x}$ \\
\hline 2. & Algorithm Deutsch Martin & $\mathrm{x}$ & - \\
\hline 3. & ASME diagram & $\mathrm{x}$ & - \\
\hline 4. & Benchmarking & - & $\mathrm{x}$ \\
\hline 5. & Brainstorming & $\mathrm{x}$ & $\mathrm{x}$ \\
\hline 6. & Brainwriting (635) & - & $\mathrm{x}$ \\
\hline 7. & Break point & $\mathrm{x}$ & $\mathrm{x}$ \\
\hline 8. & Business plan & - & $\mathrm{x}$ \\
\hline 9. & Career plan & $\mathrm{x}$ & - \\
\hline 10 . & Check list & $\mathrm{x}$ & $\mathrm{x}$ \\
\hline 11. & Crawford technique & - & $\mathrm{x}$ \\
\hline 12. & Critical path & - & $\mathrm{x}$ \\
\hline 13. & Data flow diagram & $\mathrm{x}$ & $\mathrm{x}$ \\
\hline 14. & Decisional simulation & $\mathrm{x}$ & - \\
\hline 15. & Decisional table & $\mathrm{x}$ & - \\
\hline 16. & Decisional tree & $\mathrm{x}$ & $\mathrm{x}$ \\
\hline 17. & Delbecq & $\mathrm{x}$ & $\mathrm{x}$ \\
\hline 18. & Delegation & $\mathrm{x}$ & $\mathrm{x}$ \\
\hline 19. & Diagnosis analysis & $\mathrm{x}$ & $\mathrm{x}$ \\
\hline 20. & Discovery matrix & $\mathrm{x}$ & - \\
\hline 21. & Document analysis & $\mathrm{x}$ & $\mathrm{x}$ \\
\hline 22. & ELECTRE & $\mathrm{x}$ & $\mathrm{x}$ \\
\hline 23. & Extrapolation & $\mathrm{x}$ & $\mathrm{x}$ \\
\hline 24. & Focus group & $\mathrm{x}$ & $\mathrm{x}$ \\
\hline 25 . & Functional evaluation & $\mathrm{x}$ & - \\
\hline 26. & Gantt graphic & - & $\mathrm{x}$ \\
\hline 27. & Global evaluation & $\mathrm{x}$ & - \\
\hline 28. & Gordon technique & - & - \\
\hline 29. & Hyjmans graphic & - & $\mathrm{x}$ \\
\hline 30. & Interface analysis & - & $\mathrm{x}$ \\
\hline 31. & Interview & $\mathrm{x}$ & $\mathrm{x}$ \\
\hline 32. & Job analysis & $\mathrm{x}$ & - \\
\hline 33. & Job enrichment & $\mathrm{x}$ & - \\
\hline 34. & Just in time & $\mathrm{x}$ & - \\
\hline 35. & KAIZEN & - & $\mathrm{x}$ \\
\hline 36. & LIFO & $\mathrm{x}$ & - \\
\hline 37. & Management by project & - & $\mathrm{x}$ \\
\hline 38. & Management by budgets & - & $\mathrm{x}$ \\
\hline 39. & Manager diagram & $\mathrm{x}$ & $\mathrm{x}$ \\
\hline 40. & Markowicz method & $\mathrm{x}$ & - \\
\hline 41. & Meeting technique & $\mathrm{x}$ & $\mathrm{x}$ \\
\hline 42. & Monte Carlo technique & $\mathrm{x}$ & - \\
\hline 43. & Organigram & - & $\mathrm{x}$ \\
\hline 44. & Organizational culture audit & - & $\mathrm{x}$ \\
\hline
\end{tabular}


Table 11.6 (Continued)

\begin{tabular}{|c|c|c|c|}
\hline & Management Tools & $\begin{array}{l}\text { Managerial } \\
\text { Synapse } \\
2\end{array}$ & $\begin{array}{l}\text { Company-Relevant } \\
\text { Stakeholders-Based } \\
\text { Management System } \\
3\end{array}$ \\
\hline 45 & ORTID & $\mathrm{x}$ & $\mathrm{x}$ \\
\hline 46. & PERT & - & $\mathrm{x}$ \\
\hline 47. & Phil Carol & - & $\mathrm{x}$ \\
\hline 48. & Phillips 66 & $\mathrm{x}$ & $\mathrm{x}$ \\
\hline 49. & Planus graphic & - & $\mathrm{x}$ \\
\hline 50 & Problem tracking & $\mathrm{x}$ & $\mathrm{x}$ \\
\hline 51. & Questionnaire & $\mathrm{x}$ & $\mathrm{x}$ \\
\hline 52. & Requirement workshop & - & $\mathrm{x}$ \\
\hline 53. & Root cause analysis & $\mathrm{x}$ & $\mathrm{x}$ \\
\hline 54. & Scenario method & - & $\mathrm{x}$ \\
\hline 55. & SMART model & $\mathrm{x}$ & - \\
\hline 56. & Strategic alliance & - & $\mathrm{x}$ \\
\hline 57. & SWOT analysis & - & $\mathrm{x}$ \\
\hline 58. & Synectic & $\mathrm{x}$ & $\mathrm{x}$ \\
\hline 59. & TEMPLATE grid & - & $\mathrm{x}$ \\
\hline 60. & Value analysis & $\mathrm{x}$ & - \\
\hline 61. & Value chain & - & $\mathrm{x}$ \\
\hline 62. & Vendor assessment & $\mathrm{x}$ & - \\
\hline
\end{tabular}

\section{Construction of the New Company Organizational Culture and Subcultures}

The essential role played by the organizational culture in the building and development of a performant organization was demonstrated years ago. For example, a study reported by Harvard Business School in 2003 that examined the management practice in 160 organizations over ten years found that organizational culture has significant effects on long-term economic performance. In order to generate high performance, organizational culture should be correlated with all other major components of the management system and of the company. Of course, a stakeholdersbased management system also involves a specific organizational culture, enabling it to work normally and be competitive. This new culture does not appear spontaneously; it should be constructed and developed in correlation with strategy, leadership, a stakeholders-based management system, managerial methods, and techniques, all being reshaped under a new vision focused on the company-relevant stakeholders.

Construction of the specific company organizational culture should be based on a holistic approach, considering a company as an open system and dealing with and modelling all the components of the organizational culture. In the conception of the company organizational culture focused on relevant stakeholders, it is necessary to start from the following premises: 


\section{How to Design and Build}

- stakeholders-based management system is quite different from all other "classical" management systems, the main differences being specified in Section 9.4;

- stakeholders-based management construction and work are based on the 12 new principles formulated in Section 9.5;

- stakeholders-based management system characteristics reflect the essential elements of the new "humanistic management" mentioned in Section 10.8, which should be taken into consideration in the remodelling of the organizational culture;

- specific features and components of the company organizational culture need to be changed according to the characteristics of the stakeholders-based management system.

These premises allow the main characteristics of the organizational culture in the company implementing the company-relevant stakeholders-based management system to be formulated. According to our analysis, there are 12 characteristics, enumerated in Figure 11.4 and briefly presented further below.

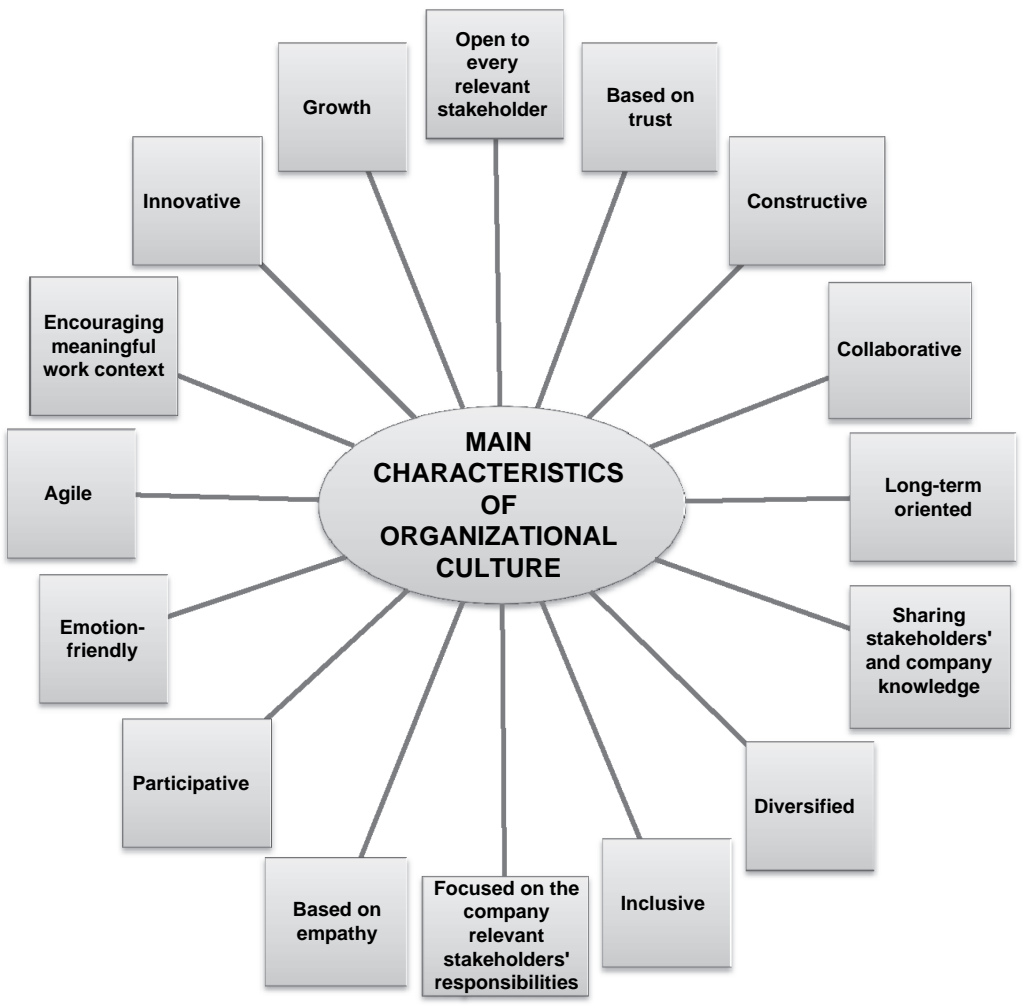

Figure 11.4 Main characteristics of organizational culture focused on the relevant stakeholders. 
- Organizational culture is open to every relevant stakeholder, internal and external, without any restriction, treating each as an important company component and encouraging the development and manifestation of company-relevant stakeholders' responsibilities.

- Trust is considered of crucial importance in the company and it is cultivated constantly at all levels - between individuals, between the organization and its components, between the company and internal and external stakeholders.

- Organizational culture is constructive, being focused on the positive approach, on the development of the company and each relevant stakeholder, encouraging everyone people implication, innovation, and performance.

- Organizational culture is collaborative, striving always to facilitate and increase positive communication, collaboration, and cooperation among all company components, at every level, centred on the internal and external relevant stakeholders. This characteristic helps company and relevant stakeholders to become a collaborative community (Adler et al., 2011).

- Performances to be achieved by the company there are approached multidimensional not only economic ones.

- Organizational culture through its values, symbols, norms, rituals, behaviours, etc. should facilitate and encourage the relevant internal and external stakeholders and, of course, the company to share their explicit and implicit knowledge, in order to generate performances and value added for all entities involved.

- Organizational culture takes into consideration and values diversity of human resources involved, of the internal and external relevant stakeholders, considering it a major source for the company development, and for "enriching" humanistic management practice.

- Inclusiveness is a major value and preoccupation for the company management, with integration of all company components, of every relevant internal and external stakeholder, being centred in managerial vision, decisions, actions, and behaviours, facilitating the increase of company synergy.

- The new approach of the company and relevant stakeholders' responsibilities (see Section 10.7) will only become operational if it is incorporated in the company's organizational culture and subcultures. Focusing the organizational culture on the companyrelevant stakeholders' responsibilities is essential for the harmonized and sustainable development of the company, internal and external stakeholders, local community, environment, etc.

- Developing empathy with the ability of company components, starting with managers, to understand and to share feelings with others is essential for the company and for each relevant stakeholder. Without constant empathy a managerial synapse, the basic 
component of the stakeholders-based management system, cannot be constructed.

- Organizational culture participative feature means a superior step in the cooperation among company human resources, involving the direct participation of every relevant stakeholder in the decisional processes regarding its activity and status in the company. A managerial synapse cannot be built and work without real participation of the relevant stakeholders involved.

- An emotion-friendly organizational culture pays major attention to the perceptions, emotions and feelings of individuals, taking care that each person feels well and is available to communicate and to cooperate with others in the work process, contributing to the development of a pleasant and productive working context for all relevant stakeholders.

- Emotional intelligence competences of managers and other individuals involved in the company work processes play a major role in the development of the emotion-friendly culture in the company.

- The agility of an organizational culture, based on the understanding of cultural dynamics (Vogel, 2017), provides to the company the necessary flexibility and speeds up its evolution in order to integrate all relevant stakeholders, including the external ones, in the company mechanisms and to enhance their functionality and performance in the conditions of win-win results.

- All the previous characteristics of a stakeholders-based organizational culture contribute to creating for company components, for its relevant stakeholders, a meaningful work context, which means an environment where they become part of creating success, cohesiveness and culture at work. Meaningful work is very motivational for the effort and the performance contributing to the individual accomplishment of relevant internal and external stakeholders.

- An innovative company culture is characterized (Pisano, 2019) by the following five features: tolerance of failure but not tolerance of incompetence, willingness to experiment but highly disciplined, psychologically save but brutal candid, collaboration but with individual accountability, and flat but strong leadership

- Organizational culture based on the relevant stakeholders is recommended to be a growth culture and not a performance-obsessed one; a growth culture, based on multifaceted motivations, involves a blend of individual and organizational components - an internal environment that is safe, a continuous learning, time limited manageable experiments with new behaviour, continuous feedback (Schwarz, 2018) - up, down, and across the organization and its relevant stakeholders. 


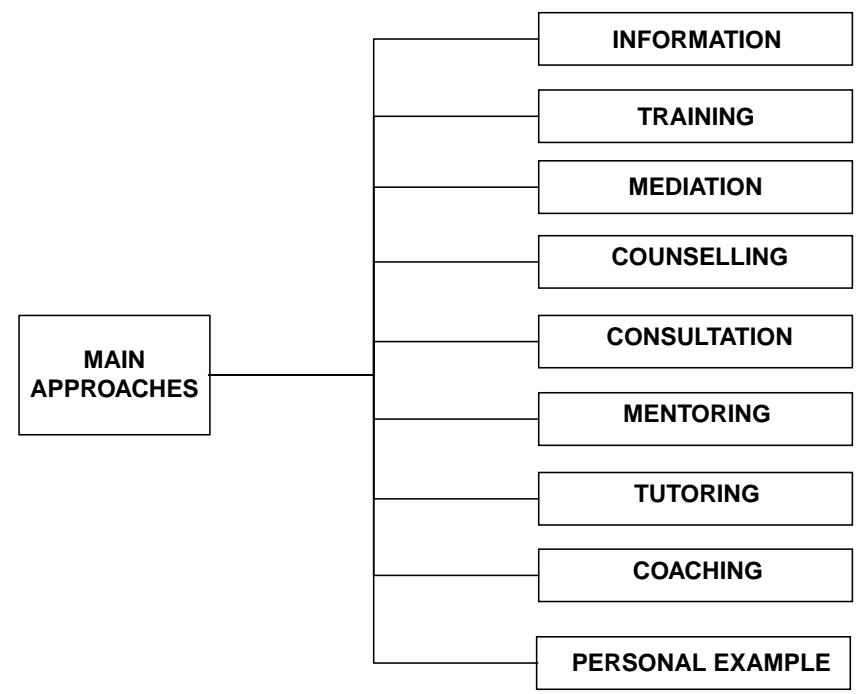

Figure 11.5 Main approaches to be used with human resources in order to reshape the company organizational culture.

In order to develop an organizational culture with the characteristics presented, it is necessary to use a set of approaches. In Figure 11.5, we enumerate a selection of them that have so far been successfully used in companies for human resources information, training and remodelling of their values, skills, behaviours, etc. We do not consider it necessary to comment on these ways, because they are used frequently in companies, being generally well known by managers and human resources management. As regards the specific aspects involved in their utilization for the development of organizational culture focused on relevant stakeholders, we formulate the following specific requirements:

- to be focused on the creation and increase of all specific characteristics of this new type of company organizational culture;

- to evaluate the organizational culture of the company in order to identify their characteristics, and its main strengths and weaknesses;

- to evaluate the features of the relevant internal and external company stakeholders, and the particular cultural problems with them;

- to identify the main subcultures inside the organizational culture of the company and of the external relevant stakeholders and their specific significant characteristics;

- to select, based on the previous elements, what ways to be used in order to develop the organizational culture at the level of the entire company and at the level of its main fields and relevant stakeholders, where subcultures have been identified; 
- to elaborate a programme for the use of the ways selected to reshape organizational culture, based on the consultation of all companyrelevant stakeholders. This programme might incorporate the elements indicated in Table 11.7. In the case of a large company, two special programmes can be elaborated - one for reshaping the entire organization culture, and the second for the reshaping of subcultures identified.

- to precede the establishment of each way and action by determining the specific content and forms to be used, based on all previous analysis, in order to maximize the positive effects on the company's organizational culture and subcultures, with reasonable costs and time consumption.

Company organizational culture reshaping should start with company managers and internal relevant stakeholders, who play a major role in the design and implementation of the stakeholders-based management system. Their personal example has a great influence on the organizational culture change, and on the operation of the managerial system focused on the company-relevant stakeholders. It is obvious that the most important is the personal example of the company CEO and of other top managers.

A major aspect to be considered in the organizational culture remodelling is the harmonization of the company organizational culture with the main subcultures involved - from the own organization and from external stakeholders. Their major characteristics should be harmonized or at least made fully compatible, developing a company stakeholders' community. Within the company, it is recommended to use predominantly the care culture style and culture results style, which are more performant (Groysberg, Lee, Price, \& Cheng, 2018).

For company managers, in order to develop the organizational culture focused on the relevant stakeholders, it could be helpful to use some methodological approaches recommended by specialists in the field for the remodelling of the company organizational culture. There are many such approaches in the speciality literature, like those elaborated by Cameron and Quinn (2011), Connors and Smith (2011), Edmonds (2014), Knight (2014), Schein (2010) and, more recently, by Groysberg et al. (2018).

The integration of the specific elements regarding company organizational culture focused on the stakeholders, indicated by us, should be very useful in improving the results achieved by company management.

Without any doubt, constructing a company organizational culture focused on the relevant stakeholders is a very complex and difficult process that needs significant costs and time. Despite these problems, the new company organizational culture should be constructed, because 
How to Design and Build 353

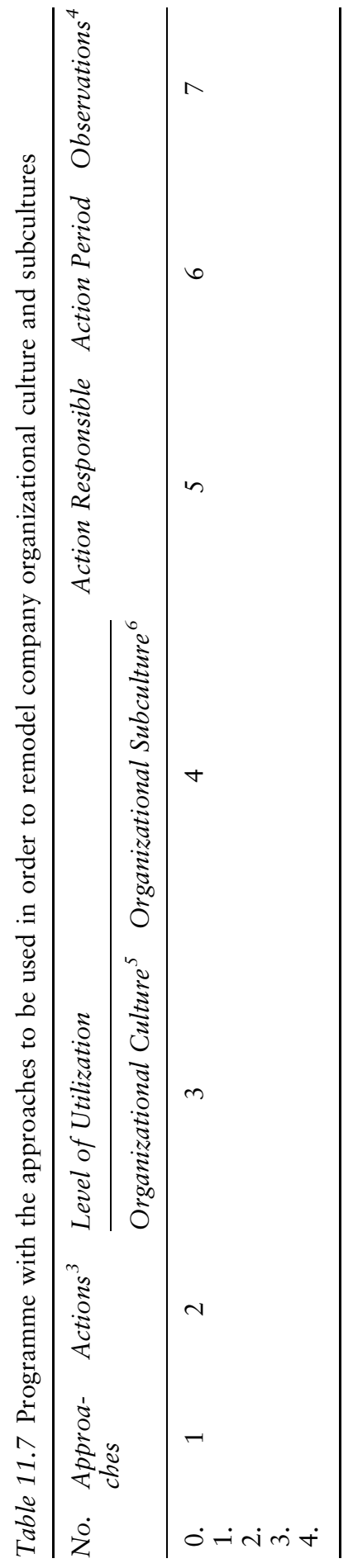




\section{How to Design and Build}

without it the company management system cannot work properly and in a performant manner. When organizational culture is properly aligned with the other components of the company it "can unleash tremendous amounts of energy toward a shared purpose and foster an organization's capacity to thrive" (Groysberg et al., 2018).

The building of the new organizational culture should be correlated with the implementation of all other major elements involved, mentioned at the beginning of this chapter - new vision and leadership, specific organization strategy, redesigned company management system, and the "arsenal" of stakeholder-focused approaches, methods, and techniques. Together, all these essential management fields represent the content of the company-relevant stakeholder-based management system.

One final remark: the design and implementation of the relevant stakeholder system is a personalized process for each interested company. Elements presented in this chapter of the book, there are just major landmarks to be used in this process. In order to achieve a competitive relevant stakeholders' company management system, the concrete approach to each organization management process and relationship is decisive, taking into consideration company and relevant stakeholders' particularities, using agile and innovative approaches.

Concomitantly, the last changes and challenges in the company environment should be taken into consideration, including those generated by the COVID-19 pandemic (see, e.g., Boston Consulting Group, 2020; Carlson-Szlezac, Reeves, \& Swartz, 2020; Chaturvedi, Dey, \& Singh, 2020; Chima \& Gutman, 2020; Gjaja, Fæste, Hansell, \& Hohner, 2020; King \& Wald, 2020; Narayandas, Hebbar, \& Li, 2020; Nicolescu, Popa, \& Dumitrascu, 2020; Pedersen \& Ritter, 2020; Radjou, 2020; Romeo, Moukanas, \& Rung, 2020; Waldron \& Wetherbe, 2020) and their major influences on the company and the internal and external relevant stakeholders.

\section{Notes}

1 Certain specialists have introduced the term "digital leadership", which is about enabling the organization to provide vision and purpose, to create conditions to experiment, to empower people to think differently and to get people to collaborate across boundaries, being quite often a distributed leadership (Kane, Palmer, Phillips, Kiron, \& Buckley, 2018).

2 For forecasting the strategic objectives and for all other quantitative elements of the strategy we recommend using not the classical "point" prediction but the "range of plausible estimates", which leave some margin of error, producing more realistic previsions, helping to create better management of the company and its relevant stakeholders. SPIES is a method specially developed by Haran and Moore (2014) for this new approach.

3 All concrete actions in order to use each approach selected will be indicated, like information meeting, seminar, training course, round table, mediation session, mentoring session, etc. 
4 Other very important aspects to be taken into consideration in the preparation of action shall be mentioned - if it is the case.

5 Participants selected for each action shall be indicated.

6 Subcultures involved, and the person who shall participate in each action shall be specified.

\section{References}

Ackermann, F., \& Eden, C. (2011). Strategic management of stakeholders: Theory and practice. Long Range Planning, 44(3), 179-196. doi:10.1016/ j.lrp.2010.08.001

Adler, P., Heckscher, C., \& Prusak, L. (2011). Building a collaborative enterprise. Harvard Business Review, 89 (7/8), 94-101.

Alexy, O., George, G., \& Salter, A. J. (2003). Cui bono? The selective revealing of knowledge and its implications for innovative activity. Academy of Management Review, 38(2), 270-291. doi:10.5465/amr.2011.0193

Appleyard, M. M., \& Chesbrough, H. W. (2017). The dynamics of open strategy: From adoption to reversion. Long Range Planning, 50(3), 310-321. doi:10.1016/j.lrp.2016.07.004

Ashkenas, R., \& Manville, B. (2018). The 6 fundamental skills every leader should practice. Harvard Business Review, 96(5). Retrieved from https:// hbr.org/2018/10/the-6-fundamental-skills-every-leader-should-practice

Ashworth, P., Bradbury, J., Feenstra, C. F. J., Greenberg, S., Hund, G., Mikunda, T., et al. (2011). Communication/engagement toolkit for CCS projects. Australia: Commonwealth Scientific and Industrial Research Organisation. Retrieved from https://www.globalccsinstitute.com/archive/hub/publications/135 71/publication-20110601-communication-engagement-toolkit.pdf

Bailey, C., \& Madden, A. (2016). What makes work meaningful - or meaningless. MIT Sloan Management Review, 57(4), 53-61.

Bonchek, M., \& Libert, B. (2017). To change your strategy, first change how you think. Harvard Business Review. Retrieved from https://hbr.org/2017/05/tochange-your-strategy-first-change-how-you-think

Boston Consulting Group. (2020). COVID-19 BCG perspectives series: Facts, scenarios and actions for leaders. Retrieved from https://media-publications. bcg.com/BCG-COVID-19-BCG-Perspectives-Version13.pdf

Bourne, L. (2009). Stakeholder relationship management: A maturity model for organisational implementation. Farnham, UK: Gower Publishing.

Brandenburg, L. (n.d.). How to capture stakeholder concerns. Retrieved from https://www.bridging-the-gap.com/capture-stakeholder-concerns/

Brown, J., \& Dillard, J. (2015). Dialogic accountings for stakeholders: On opening up and closing down participatory governance. Journal of Management Studies, 52(7), 961-985. doi:10.1111/joms.12153

Bryson, J., Patton, M. Q., \& Bowman, R. A. (2011). Working with evaluation stakeholders: A rationale, step-wise approach and toolkit. Evaluation and Program Planning, 34(1), 1-12. doi:10.1016/j.evalprogplan.2010.07.001

Bryson, J. M. (2004). What to do when stakeholders matter: A guide to stakeholder identification and analysis techniques. Public Management Review, 6(1), 21-53. doi:10.1080/14719030410001675722 


\section{How to Design and Build}

Calton, J. M. (2013). A de-centered stakeholder network path to creating mutual value: Is Wal-Mart showing the way? Proceedings of the International Association for Business and Society, 24, 200-207. doi:10.5840/iabsproc20132421

Cameron, K. S., \& Quinn, R. E. (2011). Diagnosing and changing organizational culture: Based on the competing values framework (3rd ed.). San Francisco, CA: Jossey-Bass.

Cappelli, P., \& Tavis, A. (2018). HR goes agile. Harvard Business Review, 96(2), 46-52.

Chaturvedi, H., Dey A. K., \& Singh, N. (2020). Coping with COVID-19. Global Focus the EFMD Business Magazine. Retrieved from https://www. globalfocusmagazine.com/coping-with-covid-19/

Chima, A., \& Gutman, R. (2020). What it takes to lead through an era of exponential change. Harvard Business Review. Retrieved from https://hbr.org/2 020/10/what-it-takes-to-lead-through-an-era-of-exponential-change

Clarke, A., \& MacDonald, A. (2019). Outcomes to partners in multi-stakeholder cross-sector partnerships: A resource-based view. Business \& Society, 58(2), 298-332. doi:10.1177/0007650316660534

Connors, R., \& Smith, T. (2011). Change the culture change the game. New York: Penguin Group.

Cummings, J. (2002). Engaging stakeholders in corporate accountability programmes: A cross-sectoral analysis of UK and transnational experience. Business Ethics A European Review, 10(1), 40-52. doi:10.1111/14678608.00211

Edmonds, S. C. (2014). The culture engine: A framework for driving results, inspiring your employees, and transforming your workplace. Hoboken, NJ: John Wiley \& Sons.

Fassin, Y., De Colle, S., \& Freeman, R. E. (2017). Intra-stakeholder alliances in plant-closing decisions: A stakeholder theory approach. Business Ethics A European Review, 26(2), 97-111. doi:10.1111/beer.12136

Fernández-Aráoz, C., Roscoe, A., \& Aramaki, K. (2017). Turning potential into success: The missing link in leadership development. Harvard Business Review, 95(6), 86-94.

Fontaine, C., Haarman, A., \& Schmid, S. (2006). The stakeholder theory. Retrieved from https://pdfs.semanticscholar.org/606a/828294dafd62aeda92 a77bd7e5d0a39af56f.pdf

Freeman, R. E., Harrison, J. S., Wicks, A. C., Parmar, B. L., \& De Colle, S. (2010). Stakeholder theory: The state of art. New York: Cambridge University Press.

Giannarakis, G., Garefalakis, A., Lemonakis, C., \& Konteos, G. (2017). The drivers of social responsible stock index: The case of Dow Jones sustainability index world. Corporate. Ownership \& Control, 14(2-1), 173-180. doi:1 $0.22495 / \mathrm{cocv} 14 \mathrm{i} 2 \mathrm{c} 1 \mathrm{p} 3$

Gjaja, M., Fæste, L., Hansell, G., \& Hohner, D. (2020, April 16). COVID-19: Win the fight, win the future. Boston Consulting Group. Retrieved from https://www.bcg.com/en-hu/publications/2020/covid-scenario-planning-winningthe-future-series

Groysberg, B., Lee, J., Price, J., \& Cheng, J. Y.-J. (2018). The leader's guide to corporate culture. Harvard Business Review, 96(1), 44-52. 
Hall, M., Millo, Y., \& Barman, E. (2015). Who and what really counts? Stakeholder prioritization and accounting for social value. Journal of Management Studies, 52(7), 907-934. doi:10.1111/joms.12146

Haran, U., \& Moore, D. A. (2014). A better way to forecast. California Management Journal, 57(1), 5-15. doi:10.1525/cmr.2014.57.1.5

Harraf, A., Wanasika, I., Tate, K., \& Talbott, K. (2015). Organizational agility. Journal of Applied Business Research, 31(2), 675-686. doi:10.19030/jabr.v31 i2.9160

Harrison, J. S., \& Wicks, A. C. (2013). Stakeholder theory, value and firm performance. Business Ethics Quarterly, 23(1), 97-124. doi:10.5840/beq2 0132314

Haski-Leventhal, D., Roza, L., \& Meijs, L. C. P. M. (2017). Congruence in corporate social responsibility: Connecting the identity and behavior of employers and employees. Journal of Business Ethics, 143(1), 35-51. doi:10.1 007/s10551-015-2793-z

Hautz, J., Seidl, D., \& Whittington, R. (2017). Open strategy: Dimensions, dilemmas, dynamics. Long Range Planning, 50(3), 298-309. doi:10.1016/j.lrp.2 016.12.001

Healey, M. P., \& Hodgkinson, G. P. (2017). Making strategy hot. California Management Review, 59(3), 109-134. doi:10.1177/0008125617712258

Hearn, S. (2014, September 15). Alignment, interest, influence matrix. Retrieved from https://www.outcomemapping.ca/nuggets/alignmentinterest-influence-matrix

Hernandez, M. (2019). A shared passion for place can make a business more resilient. MIT Sloan Management Review. Retrieved from https:// sloanreview.mit.edu/article/a-shared-passion-for-place-can-make-a-businessmore-resilient/

Heyden, M. L. M., Fourné, S. P. L., Koene, B. A. S., Werkman, R., \& Ansari, S. (2017). Rethinking "top-down" and "bottom-up" roles of top and middle managers in organizational change: Implications for employee support. Journal of Management Studies, 54(7), 961-985. doi:10.1111/joms.12258

Hill, L. A., \& Davis, G. (2017). The board's new innovation imperative: Directors need to rethink their roles and their attitude to risk. Harvard Business Review, 95(6), 102-109.

How to Create Stakeholder Management and Communication Plans. (n.d.). Retrieved from https://www.smartsheet.com/how-create-stakeholder-managementand-communication-plans

Huang, K.-F., Dyerson, R., Wu, L.-Y., \& Harindranath, G. (2015). From temporary competitive advantage to sustainable competitive advantage. British Journal of Management, 26(4), 617-636. doi:10.1111/1467-8551.12104

International Institute of Business Analysis. (2009). A guide to the business analysis body of knowledge (BABOK Guide). Version 2.0. Totonto, Canada: International Institute of Business Analysis.

Jarvenpaa, S. L., \& Välikangas, L. (2014). Opportunity creation in innovation networks: Interactive revealing practices. California Management Review, 57(1), 67-87. doi:10.1525/cmr.2014.57.1.67

Kane, G. C., Palmer, D., Phillips, A. N., Kiron, D., \& Buckley, N. (2018). Coming of age digitally: Learning, leadership, and legacy. MIT Sloan 


\section{How to Design and Build}

Management Review. Retrieved from https:/sloanreview.mit.edu/projects/ coming-of-age-digitally/

Knight, J. (2014). Culture that rocks: How to revolutionize your Company's culture. Winter Garden, FL: Knight Speaker LLC.

Korn Ferry. (2019). Self disrupt or be disrupted. Retrieved from https:// www.kornferry.com/self-disrupt

Lee, A., Willis, S., \& Tian, A. W. (2018). When empowering employees works, and when it doesn't. Harvard Business Review, 96(2). https://hbr.org/2018/ 03/when-empowering-employees-works-and-when-it-doesnt

Lesser, R., Reeves, M., Whitaker, K., \& Hutchinson, R. (2018, December 14). A leadership agenda for the next decade - Winning the '20s. Retrieved from https://www.bcg.com/publications/2018/winning-the-20s-leadership-agendafor-next-decade.aspx

Mitchell, R. K., Van Buren, H. J., Greenwood M., \& Freeman, R. E. (2015). Stakeholder inclusion and accounting for stakeholders. Journal of Management Studies, 52(7), 851-877. doi:10.1111/joms.12151

Mitchell, R. K., Weaver, G. R., Agle, B. R., Bailey, A. D., \& Carlson, J. (2016). Stakeholder agency and social welfare: Pluralism and decision making in the multi-objective corporation. Academy of Management Review, 41(2), 252-275. doi: 10.5465/amr.2013.0486

Narayandas, D., Hebbar, V., \& Li., L. (2020). Lessons from Chinese companies' response to Covid-19. Harvard Business Review. Retrieved from https:// hbr.org/2020/06/lessons-from-chinese-companies-response-to-covid-19

Nicolescu, O., \& Verboncu, I. (2008). Fundamentele Managementului Organizatiei. Bucuresti, Romania: Editura Universitara.

Pisano, G. P. (2019). The hard truth about innovative cultures. Harvard Business Review, 97(1), 62-71.

Radjou, N. (2020). The rising frugal economy. MIT Sloan Management Review. Retrieved from https://sloanreview.mit.edu/article/the-rising-frugal-economy/

Ready, D. A., Cohen, C., Kiron, D., \& Pring, B. (2020, January). The new leadership playbook for digital age. MIT Sloan Management Review. Retrieved from https:// sloanreview.mit.edu/projects/the-new-leadership-playbook-for-the-digital-age/? gclid=CjwKCAjwg6b0BRBMEiwANd1_SE8dUmZetK_peLCkKBI6abknYo6vYc KUtSDNbE_MYo5CTuqs4SF6yRoCxlwQAvD_BwE

Repenning, N. P., Kieffer, D., \& Repenning, J. (2018). A new approach to designing work. MIT Sloan Management Review, 59(2), 29-38.

Rogers, K. (2018). Do your employees feel respected? Harvard Business Review, 96(4), 62-71.

Romeo, J., Moukanas, H., \& Rung, G. (2020). The age of accelerating strategy breakthroughs. MIT Sloan Management Review. Retrieved from https://sloanreview.mit.edu/article/the-age-of-accelerating-strategy-breakthroughs/

Sawhney, M., Wolcott, R. C., \& Arroniz, I. (2006). The 12 different ways for companies to innovate. MIT Sloan Management Review, 47(3), 75-81.

Schein, E. H. (2010). Organizational Culture and Leadership (4th ed.). San Francisco, CA: Jossey-Bass.

Schwarz, T. (2018). Create a growth culture, not a performance-obsessed one. 
Harvard Business Review, 96(2). Retrieved from https://hbr.org/2018/03/ create-a-growth-culture-not-a-performance-obsessed-one

Sibony, O., Lovallo, D., \& Powell, T. C. (2017). Behavioral strategy and the strategic decision architecture of the firm. California Management Review, 59(3), 5-21. doi:10.1177/0008125617712256

Skolits, G. J., \& Boser, J. A. (2018). Using an evaluation hotline to promote stakeholders involvement. American Journal of Evaluation, 29(1), 58-70. doi: $10.1177 / 1098214007312777$

Stakeholder Analysis. (n.d.). Retrieved from https://www.slideshare.net/ dsaadeddin/stakeholder-analysis-52893836

Stakeholder Analysis, Project Management, Templates and Advice. (n.d). Retrieved from https://www.stakeholdermap.com/stakeholder-analysis.html

Stakeholder Management Strategy Template. (n.d.). Retrieved from https:// www.projectmanagementdocs.com/template/project-initiation/stakeholdermanagement-strategy/\#axzz6NTp7qXI3

Teece, D., Peteraf, M., \& Leih, S. (2016). Dynamic capabilities and organizational agility: Risk, uncertainty and entrepreneurial management in the innovation economy. California Management Review, 58(4), 13-35. 10.1525/ cmr.2016.58.4.13

Vandenbussche, L., Edelenbos, J., \& Eshuis, J. (2017). Pathways of stakeholders' relations and frames in collaborative planning practices: A framework to analyse relating and framing dynamics. Planning Theory, 16(3), 233-254. doi: $10.1177 / 1473095215620150$

Vogel, D. J. (2017). Haas research on leadership: An introduction. California Management Review, 60(1), 5-7. doi:10.1177/0008125617735339

Waldron, T., \& Wetherbe, J. (2020). Ensure that your customer relationships outlast coronavirus. Harvard Business Review. Retrieved from https:// hbr.org/2020/04/ensure-that-your-customer-relationships-outlast-coronavirus

Weber, Y., \& Tarba, S. Y. (2014). Strategic agility: A state of the art introduction to the special section on strategic agility. California Management Review, 56(3), 5-12. doi: $10.1525 / \mathrm{cmr} .2014 .56 .3 .5$

Wellman, N. (2017). Authority or community? A relational models theory of group-level leadership emergence. Academy of Management Review, 42(4), 596-617. doi:10.5465/amr.2015.0375

Westerman, G. (2018). Your company doesn't need a digital strategy. MIT Sloan Management Review, 59(3), 14-15.

Youmans, T., \& Tomlinson. B. (2018). Six reasons why companies should start sharing their long-term thinking with investors. MIT Sloan Management Review. Retrieved from https://sloanreview.mit.edu/article/six-reasons-whycompanies-should-start-sharing-their-long-term-thinking-with-investors/ 